\title{
过渡金属催化的羰基化的杂环化合成和官能团化
}

\author{
尹志平门王泽超门吴小锋*
}

(Leibniz-Institut für Katalyse e.V. an der Universität Rostock, Albert-Einstein-Straße 29a, 18059 Rostock, Germany)

\begin{abstract}
摘要 杂环化合物广泛的存在于天然产物、药物、有机材料以及其他官能团化的分子中. 所以发展杂环合成的新的方 法学有着极其重要的意义. 在所有的有机合成策略中, 过渡金属催化的反应，由于其相对温和的反应条件和高效的原 子利用率，无疑是一种理想的选择. 这其中，过渡金属催化的羰基化反应又是一个比较理想的反应. 自从 20 世纪 30 年 代首度报道以来, 羰基化反应经历了长足的发展. 时至今日, 各种羰基化反应类型都得到发展. 反应底物也囊括了卤 代芳烃、烯烃、炔烃及其它未经活化的化合物. 羰基来源也从一氧化碳气体拓展到了其他原位释放一氧化碳的化合物, 例如甲酸、醇、醴、生物质等. 对我们课题组在过去 5 年中在过渡金属催化的羰基化合成杂环及杂环的官能团化领域 的工作进行了总结. 使用铜、钯、铑、钓和铱作为催化剂, 基于碳卤键和碳氢键的活化, 各种杂环化合物都能被高效的 合成.
\end{abstract}

关键词＼cjkstart过渡金属催化; 羰基化; 杂环合成; 羰基来源; 环化反应; 多米诺反应

\section{Transition-Metal-Catalyzed Carbonylative Synthesis and Functionalization of Heterocycles}

\author{
Yin, Zhiping ${ }^{\dagger}$ \\ Wang, Zechao ${ }^{\dagger}$ \\ $\mathrm{Wu}$, Xiao-Feng* \\ (Leibniz-Institut für Katalyse e.V. an der Universität Rostock, Albert-Einstein-Straße 29a, 18059 Rostock, Germany)
}

\begin{abstract}
Heterocycles are ubiquitous in natural products, pharmaceuticals, organic materials, and numerous functional molecules. These structural units probably constitute the largest and most varied family of organic compounds. Hence the development of new procedures for heterocycles synthesis has been a hot research topic for over centuries. Among all the new synthetic methods, transition-metal-catalyzed reactions are attractive. Those reactions can formulate complicated heterocycles efficiently from available starting materials under mild conditions and atom economical routes. Among them, transition-metal-catalyzed carbonylation reaction has become an efficient and useful tool in organic synthesis since the first hydroformylation reaction developed by W. Reppe at BASF in the 1930s. Since then impressive progress has been achieved in this area. In nowadays, various types of carbonylation reactions were established. Substrates including aryl halides, olefins, alkynes or simply $\mathrm{C}-\mathrm{H}$ bond can be activated and produce the corresponding carbonyl-containing compounds smoothly. On the other hand, carbon monoxide was discovered and identified in the 18th century. Since the first applications in industry around 80 years ago, academic and industrial laboratories have explored uses of $\mathrm{CO}$ in chemical reactions broadly. However, because of the special physical properties of $\mathrm{CO}$, organic chemists were often reluctant to apply carbonylations frequently in laboratories. Hence, different kinds of $\mathrm{CO}$ surrogates were developed and applied in carbonylation reactions, such as metal carbonyl compounds $\mathrm{M}(\mathrm{CO})_{x}$, formates, alcohols, formic acid, aldehyde, biomass and carbon dioxide. Those CO surrogates offer interesting opportunities for carbonylation reactions. This account mainly outlines our progress in the development of transition-metal-catalyzed carbonylative synthesis and functionalization of heterocycles from 2012 to 2018 . With copper, palladium, rhodium, ruthenium and iridium as the catalysts and relying on the activation of carbon-halogen and carbon-hydrogen bonds, we are able to synthesis various of heterocycles by using $\mathrm{CO}$ gas or $\mathrm{CO}$ surrogates as the $\mathrm{C} 1$ building blocks.

Keywords transition metal catalyst; carbonylation; heterocycle synthesis; CO surrogates; cyclization; Cascade reaction
\end{abstract}

\section{Introduction}

Heterocyclic compounds are an integral part of many biologically active molecules and many currently marketed drugs hold heterocycles as their core structure. Hence, extensive efforts have been focused on the development of efficient approaches for the synthesis of heterocycles.

\footnotetext{
* Corresponding author. E-mail: xiao-feng.wu@catalysis.de

Received September 4, 2018; revised September 26, 2018; published online October 19, 2018.

共同第一作者(These authors contributed equally to this work).
} 
Considering the synthetic value of carbonylation reactions and the importance of heterocycles preparation, the merging of these two topics offers interesting possibilities for organic synthesis. Although a number of reviews on catalytic carbonylation reactions as well as on the synthesis of heterocycles already exist, no general summary on transition metal catalyzed carbonylation synthesis of heterocycles via activation of $\mathrm{C}-\mathrm{H}$ or $\mathrm{C}-\mathrm{X}$ bond by using $\mathrm{CO}$ gas and $\mathrm{CO}$ surrogates have been published so far. ${ }^{[1]}$ Here we report a summary of our group's recent progress in this area, and this account mainly divided into four parts according to the different bonds activated $(\mathrm{C}-\mathrm{H}$ or $\mathrm{C}-\mathrm{X})$ and the different $\mathrm{CO}$ sources applied ( $\mathrm{CO}$ gas or $\mathrm{CO}$ surrogates).

\section{Synthesis of heterocycles through ac- tivation of $\mathrm{C}-\mathrm{X}$ with $\mathrm{CO}$ gas}

2.1 Synthesis of five-membered heterocycles through activation of $\mathrm{C}-\mathrm{X}$ with $\mathrm{CO}$ gas

Furanones are important compounds with various biological activities, such as anti-inflammatory, cardiotonic, analgesic, anticonvulsant and antiviral activity. In 1993, Eaton group $^{[2 \mathrm{a}]}$ reported a catalytic iron-catalyzed $[4+1]$ cycloaddition with allenyl ketones, aldehydes, and carbon monoxide to give alkylidenebutenolides. Our group developed a general and efficient palladium-catalyzed carbonylation coupling reaction of aryl iodides with benzyl acetylenes under CO atmosphere. Various furanones were prepared in excellent yields from the corresponding benzyl acetylenes. Interestingly, when aliphatic alkynes were used as substrates, the corresponding alkynones were formed in good yields, which might come from the fact that the benzylic hydrogen atoms are more activated than the aliphatic hydrogen atoms.

Meanwhile, density functional theory (DFT) calculations were also carried out to understand the reaction pathway. The most probable reaction mechanism is proposed (Scheme 1). The reaction begins with the oxidative addition of $\mathrm{PhX}$ to the $\mathrm{Pd}^{0}$ center, followed by $\mathrm{CO}$ coordination and insertion to form acyl complex $\mathbf{1}$. Then complex 2 are formed through a ligand exchange of $\mathrm{X}$ with the alkynyl moiety, which undergoes reductive $\mathrm{C}-\mathrm{C}$ coupling to afford complex $\mathbf{3}$. The isomerization of complex $\mathbf{3}$ forms complex 4. Further $\mathrm{CO}$ insertion forms complex 5 and subsequent reductive $\mathrm{CO}$ coupling forms the product and regenerate the catalyst. ${ }^{[2 \mathrm{~b}]}$

For the synthesis of some other furanone derivatives, a new palladium-catalyzed double carbonylation procedure by coupling of aryl halides, $\mathrm{CO}$ and terminal alkenes was developed later (Scheme 2). Different aryl bromides and iodides transformed into the corresponding furanones in modest and good yields. Using this new atom-efficient carbonylation reaction, a total of 18 different 4-arylfuranones were synthesized in up to $87 \%$ yield. ${ }^{[3]}$

Meanwhile, a one-pot synthesis of benzoxazoles from

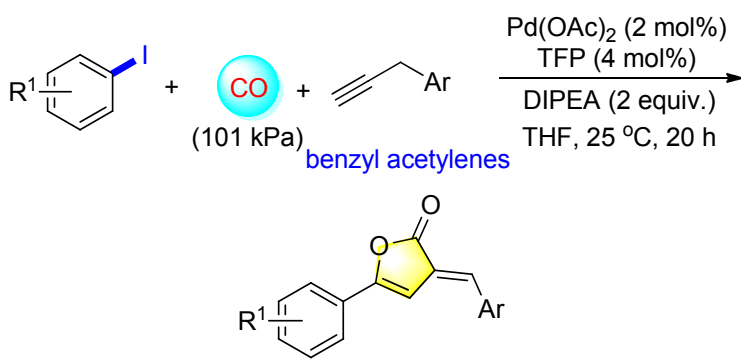

18 examples, $82 \% \sim 99 \%$ yield
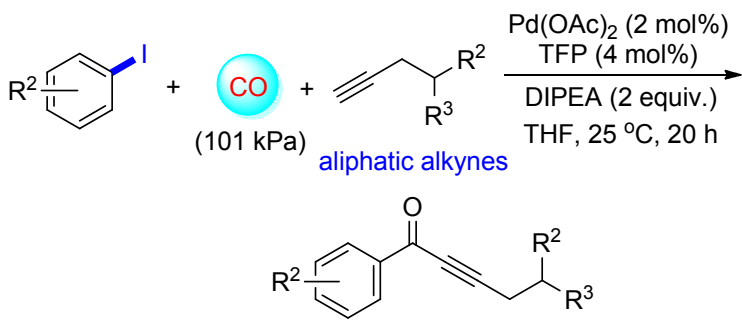

6 examples, $62 \% \sim 88 \%$ yield

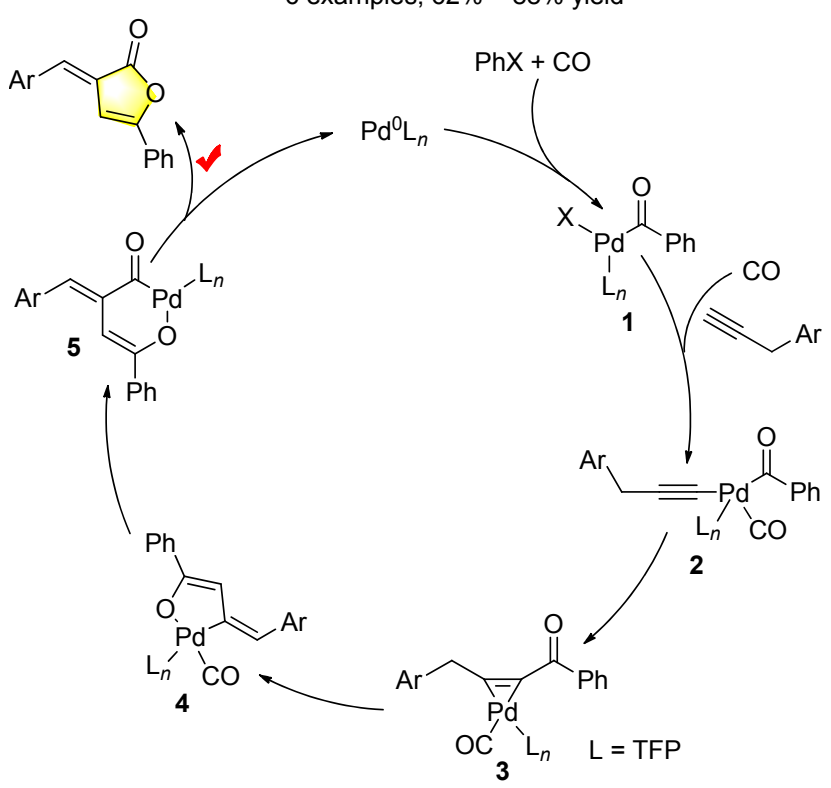

Scheme 1 Palladium-catalyzed carbonylative coupling of aryl iodides and acetylenes

aryl bromides and 1,2-dibromobenzenes (Scheme 3) was developed. The first step is a palladium-catalyzed aminocarbonylation of bromobenzene under $200 \mathrm{kPa}$ of $\mathrm{NH}_{3}$ and $\mathrm{CO}$ in 1,4-dioxane, which gave the desired product benzamide successfully. Then treated this crude mixture with $\mathrm{CuI} / \mathrm{DMEDA} / \mathrm{K}_{2} \mathrm{CO}_{3}$ under $110{ }^{\circ} \mathrm{C}$, various 2-arylsubstituted benzoxazoles were produced in moderate to good yield. ${ }^{[4]}$ In addition, a general palladium-catalyzed carbonylation synthesis of different 2-aryloxzolines was also represented. Bromobenzene and 2-chloroethylamine were selected as the substrates, various five-memberedring oxazolines were synthesized successfully under 1.0 $\mathrm{MPa} \mathrm{CO}$ in the presence of $\mathrm{Pd}(\mathrm{OAc})_{2} / \mathrm{BuPAd}_{2} / \mathrm{NEt}_{3}$ with the yield up to $89 \%$. ${ }^{[5]}$ 

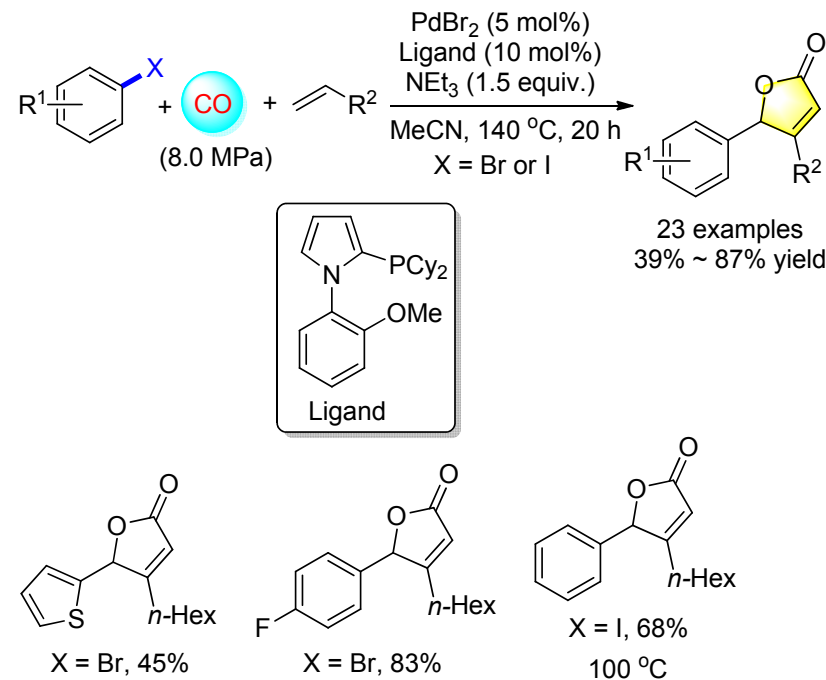

Scheme 2 Synthesis of furanones from aryl halides and alkenes
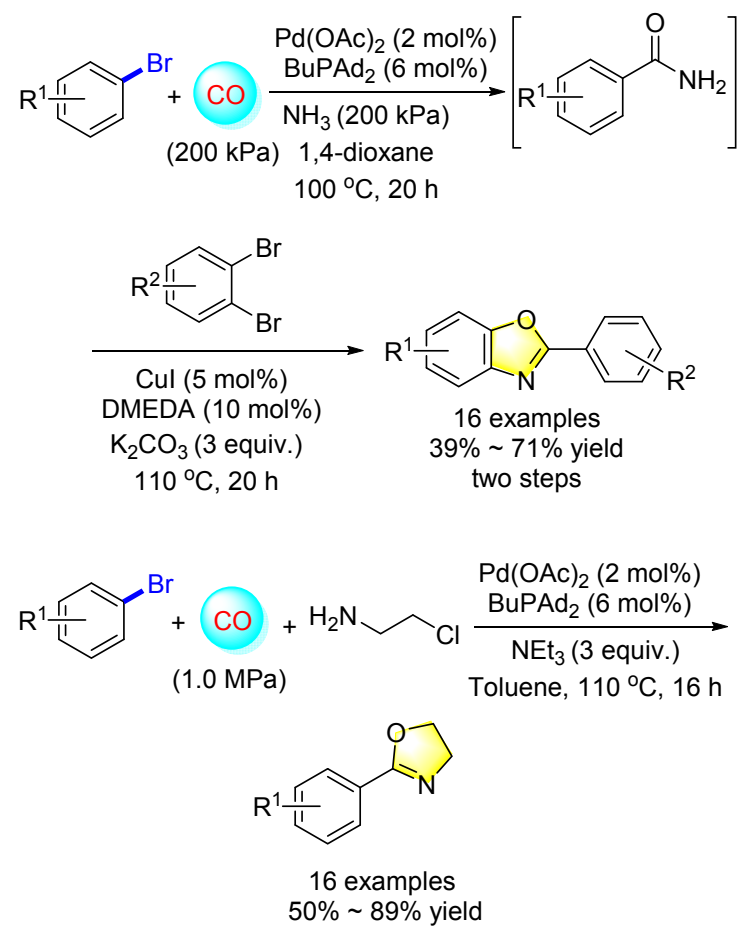

Scheme 3 Synthesis of benzoxazoles from aryl bromides

Due to our ongoing interest in the carbonylation reactions and the crucial of furans, a palladium-catalyzed double carbonylation coupling of aryl halides and aliphatic alkynes to give furan heterocycles was developed (Scheme 4). The most sensible mechanism based on detailed DFT calculation results is proposed. The first step is the Sonogashira-type formation of alkynone intermediate 7, and then acyl insertion to the isomerized allene $\mathbf{8}$ from the formed alkynone 7. The crucial step is a concerted ringclosure and $\mathrm{Pd}$ shift, which is also the rate-determining step. The last step is $\beta$-H elimination with the formation of furan product and the regeneration of the catalyst by the base. ${ }^{[6]}$

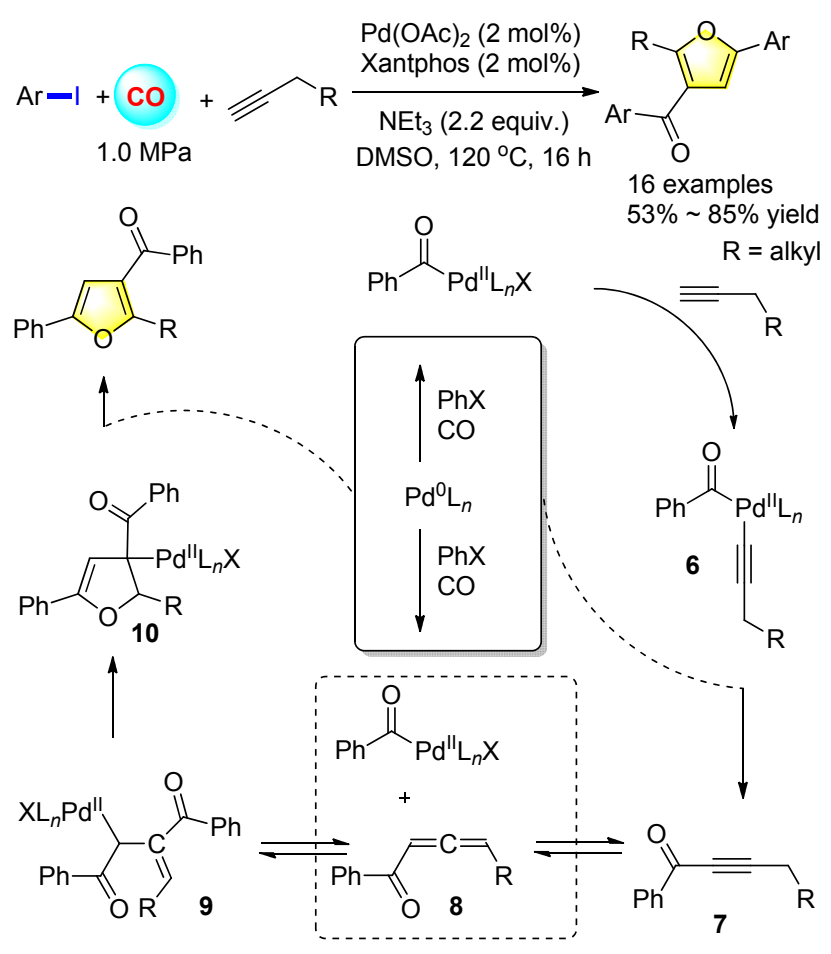

Scheme 4 Synthesis of furan derivatives

Imide derivatives, especially phthalimides, are an important class of compounds with various biological activities. A convenient double carbonylation of $o$-dibromobenzenes with various 2 -amino pyridines by using $\mathrm{Pd}(\mathrm{OAc})_{2}$ and cataCXium $\mathrm{A}$ as the catalyst system was estabilished (Scheme 5). More importantly, this procedure is also suitable for the synthesis of biological compounds containing phthalimide groups. ${ }^{[7]}$ Interestingly, after changing the base from $\mathrm{NEt}_{3}$ to 1,8-diazabicyclo[5.4.0] undec-7-ene (DBU) or 1,5-diazabicyclo[4.3.0]non-5-ene (DBN), they were found act as both base and nucleophile in the reaction. Hydrolysis

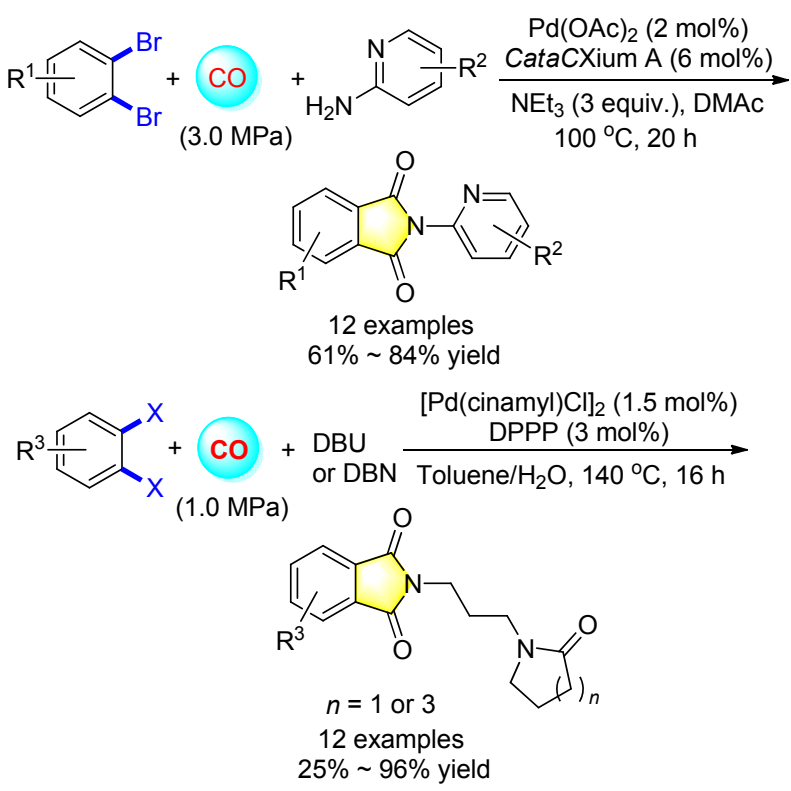

Scheme 5 Synthesis of imide derivatives 
leading to the ring opening reaction of DBU or DBN, different caprolactam and butyrolactam were synthesized in one-pot with the yield up to $96 \%{ }^{[8]}$

The application of encapsulation has been extended from pharmacy to other realms. In organic synthesis, reagent capsules can help to resolve the compatibility problem of reagents in multicomponent processes. A facile method for encapsulating smelly liquid sulfur chemicals and its application for the synthesis of thiophenes and benzothiophenes was estabilished (Scheme 6). In this process, the capsule plays a crucial role in solving the selectivity of multicomponent reactions as well as avoiding the deactivation of catalysts. ${ }^{[9]}$
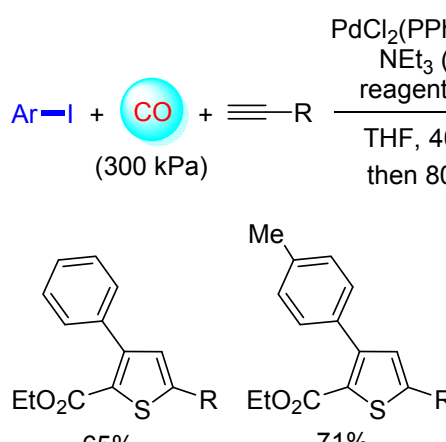

$\mathrm{Cl}_{2}\left(\mathrm{PPh}_{3}\right)_{2}(2 \mathrm{~mol} \%)$ $\mathrm{NEt}_{3}$ (3 equiv.)

$\mathrm{Ar}-\mathrm{I}+\mathrm{CO}+\equiv \mathrm{R} \underset{\mathrm{THF}, 40^{\circ} \mathrm{C}, 14 \mathrm{~h}}{\stackrel{\text { reagent capsule } \mathrm{A}}{\longrightarrow}}$

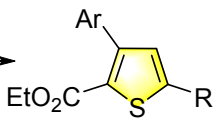

33 examples $44 \% \sim 75 \%$ yield

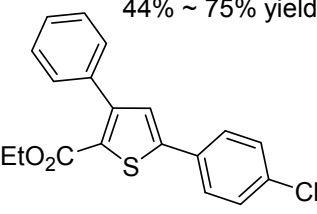

$73 \%$
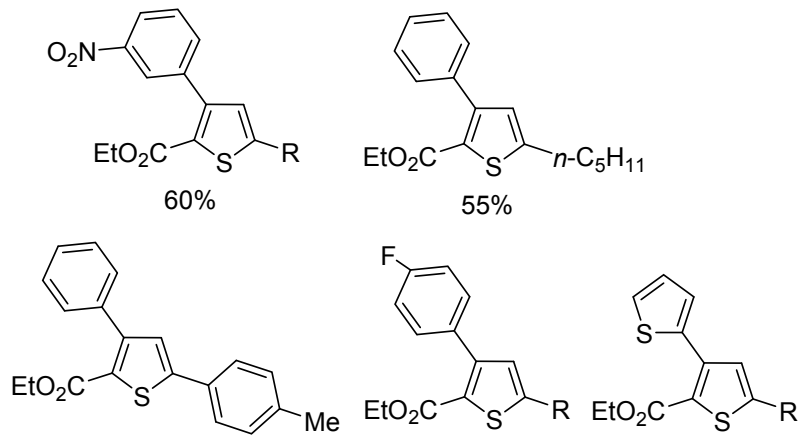

$68 \%$

$52 \%$

$55 \%$

Reagent capsule $\mathrm{A}=\mathrm{EtOH}(0.20 \mathrm{~mL})$ solution of ethyl thioglycolate $(0.55 \mathrm{mmol})$ and $\mathrm{DBU}(0.55 \mathrm{mmol})$

Scheme 6 Synthesis of thiophenes derivatives

\subsection{Synthesis of six-membered heterocycles through activation of $\mathrm{C}-\mathrm{X}$ with $\mathrm{CO}$ gas}

Flavones are an important class of products with a range of biological activities. In view of the structure of flavones, carbonylation reactions should be an efficient method for their construction. Actually, the application of carbonylation reaction in flavone synthesis has been shown by different groups, ${ }^{[10]} 2$-iodophenol derivatives and terminal acetylenes were used as start materials in these reactions. In 2012, the first carbonylative reaction of bromobenzene and hydroxyacetophenone was reported, the yield of the desired products can be up to $85 \%$ when DPPB and DBU were used as the ligand and base (Scheme 7). Different bromobenzenes including hetero-bromobenzenes were transformed into the corresponding flavones in moderate to good yields. ${ }^{[1]}$ Considering for the advantages of heterogeneous catalysts, we also developed a highly efficient and

selective $\mathrm{Pd} / \mathrm{C}$ catalyzed cyclo-carbonylation reaction of 2-iodophenol and ethynylbenzene. $\mathrm{Et}_{2} \mathrm{NH}$ was the best base and gave the desired product up to $98 \%$ yield. Both aromatic terminal acetylenes and aliphatic terminal acetylenes worked well in this condition, gave the corresponding flavones in $61 \% \sim 98 \%$ yields. Furthermore, $\mathrm{Pd} / \mathrm{C}$ as the heterogeneous catalysts, the reusability experiment was tested and the yield was 55\% after five times running. ${ }^{[12]}$
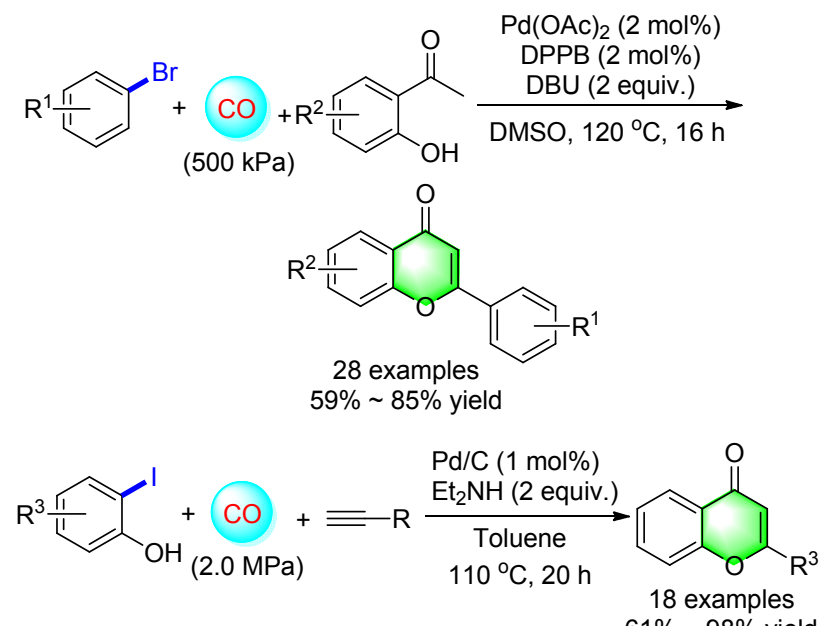
$61 \% \sim 98 \%$ yield

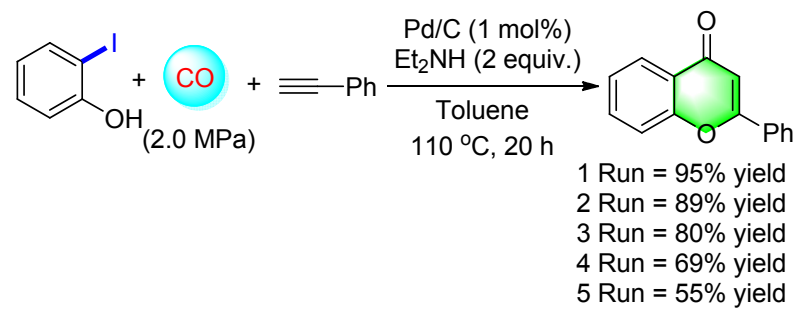

Scheme 7 Synthesis of flavones derivatives

Regarding the synthesis of 2,3-disubstituted chromones, we also discovered an unexpected palladium-catalyzed carbonylation reaction from 2-bromofluorobenzenes and ketones (Scheme 8). According to the results of control experiments, the possible reaction mechanism was proposed. The first step is a palladium catalyzed carbonylative arylation of deoxybenzoin generated an enol ester $\mathbf{1 3}$ instead of a 1,3-diketone. Then this carbonylation event was followed by the Claisen-Hasse rearrangement and followed an intramolecular $\mathrm{S}_{\mathrm{N}} \mathrm{Ar}$ reaction to give the product chromones. The reaction displays good tolerance to various substituent groups at different positions on the start materials in moderate to good yield. ${ }^{[13]}$

Quinazolinones are an important class of heterocycle, and many synthetic procedures have been developed for their preparation. Among them, 2-aminobenzamides with benzyl alcohols, acyl chlorides or their derivatives are the typical methodologies. From a synthetic point of view and the significant of carbonylation transformations, our group established a series of elegant palladium-catalyzed carbonylation coupling system for the synthesis of different quinazolinones. In 2014, a four-component method for the synthesis of quinazolinones was developed (Scheme 9). By 

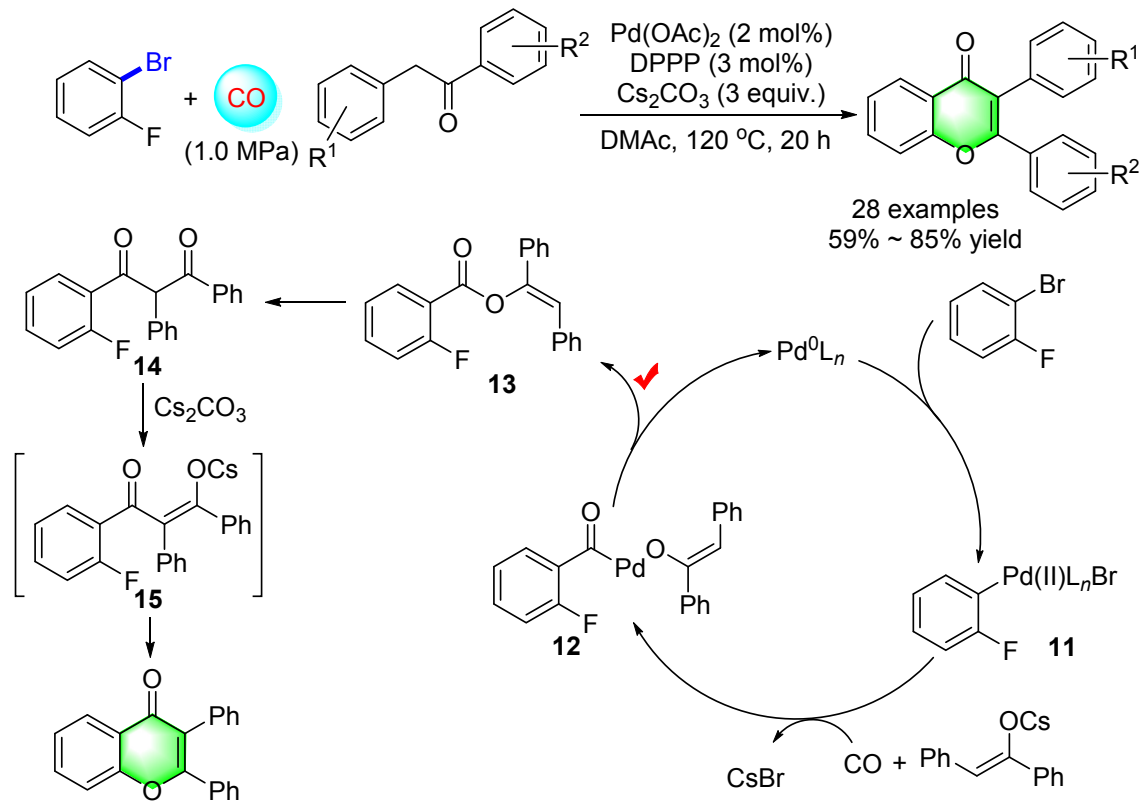

Scheme 8 Synthesis of 2,3-disubstituted chromones

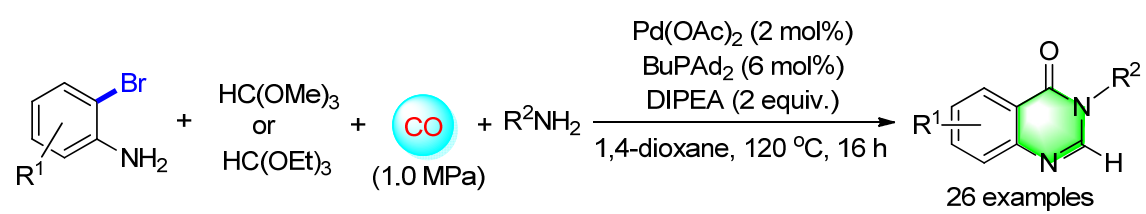<smiles>O=c1c2ccccc2ncn1-c1ccccc1</smiles>

$92 \%$<smiles>O=c1c2ccccc2ncn1Cc1cccnc1</smiles>

$69 \%$<smiles>O=c1c2ccccc2ncn1-c1ccccn1</smiles>

$68 \%$<smiles>Cc1ccc2c(=O)n(-c3ccccc3)cnc2c1</smiles>

$70 \%$<smiles>O=c1c2ccccc2ncn1Cc1ccccc1</smiles>

$60 \%$<smiles>O=c1c2cccc(F)c2ncn1-c1ccccc1</smiles>
$60 \% \sim 92 \%$ yield

Scheme 9 Synthesis of quinazolinones<smiles>CCCn1cnc2ccccc2c1=O</smiles>

$84 \%$<smiles>O=c1c2cccnc2ncn1-c1ccccc1</smiles>

using $N, N$-diisopropylethylamine (DIPEA), $\operatorname{Pd}(\mathrm{OAc})_{2} /$ $\mathrm{BuPAd}_{2}$ as the catalyst system, 2-bromoaniline, aniline, triethyl orthoformate and $\mathrm{CO}$ proceeded smoothly in 1.4-dioxane gave 3-phenyl-4(3H)-quinazolinone up to $92 \%$ yield. Aromatic amines and hetero-aromatic amines with different substitutes participated smoothly in our condition. Notably, the benzylamines and aliphatic amines were also successfully transformed into the corresponding quinazolinones. ${ }^{[14]}$

Given the advantage of heterogeneous catalysts, the application of $\mathrm{Pd} / \mathrm{C}$ as a heterogeneous catalyst for the fourcomponent carbonylation reaction was studied. To our delight, when 2-iodoaniline was selected as model substrate, in the presence of DIPEA, $\mathrm{Pd} / \mathrm{C}$ and toluene the desired product was provided in $96 \%$ yield (Scheme 10 ). The result of substrates scoping showed a good tolerance of various aromatic amine derivatives and aliphatic amines. Moreover, $\mathrm{Pd} / \mathrm{C}$ was found to be effectively recy- cled for four consecutive cycles in our recycling experiments. ${ }^{[15]}$

Following the same idea, an efficient novel palladium catalyzed carbonylation/intramolecular nucleophilic aromatic substitution reaction to give pyridoquinazolones has been developed (Scheme 11). The reaction showed good regioselectivity for the formation of both linear and angular fused isomers, which could simply be controlled by the choice of base ( $\mathrm{NEt}_{3}$ or DBU). Whereas in the presence of DBU the linear products 16 were obtained, $\mathrm{NEt}_{3}$ gave the angular derivatives $\mathbf{1 7}$. The strength of the base may play a pivotal role in this process (the acidities of the conjugate acids are $\mathrm{p} K_{\mathrm{a}}=12$ and 10.8 for $\mathrm{DBU}$ and $\mathrm{NEt}_{3}$ (triethylamine), respectively). Indeed, NMR spectroscopic experiments confirmed that DBU deprotonates 2-aminopyridine to a major extent to afford the 2-imino- $2 \mathrm{H}$-pyridin-1-ide which was not observed in the presence of $\mathrm{NEt}_{3}{ }^{[16]}$ 

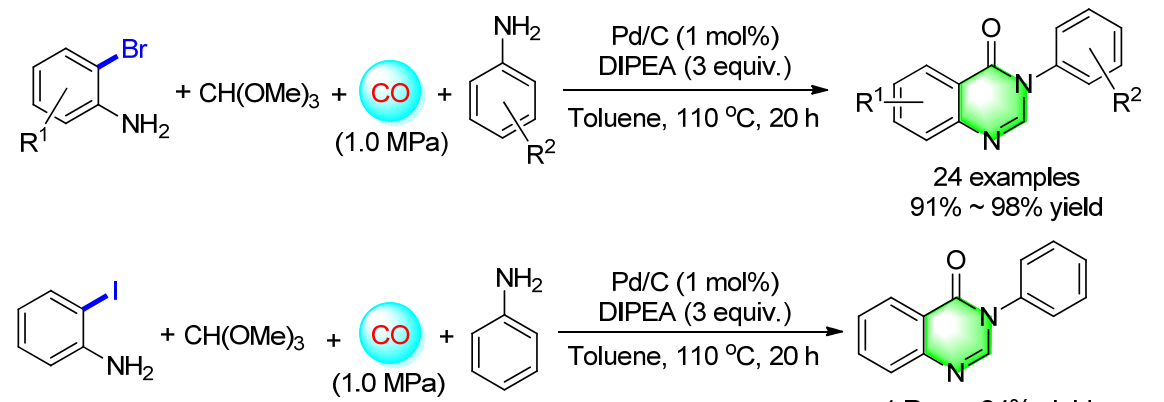

$$
\begin{aligned}
& 1 \text { Run }=94 \% \text { yield } \\
& 2 \text { Run }=81 \% \text { yield } \\
& 3 \text { Run }=76 \% \text { yield } \\
& 4 \text { Run }=64 \% \text { yield } \\
& 5 \text { Run }=51 \% \text { yield }
\end{aligned}
$$

Scheme $10 \mathrm{Pd} / \mathrm{C}$ catalyzed the synthesis of quinazolinones
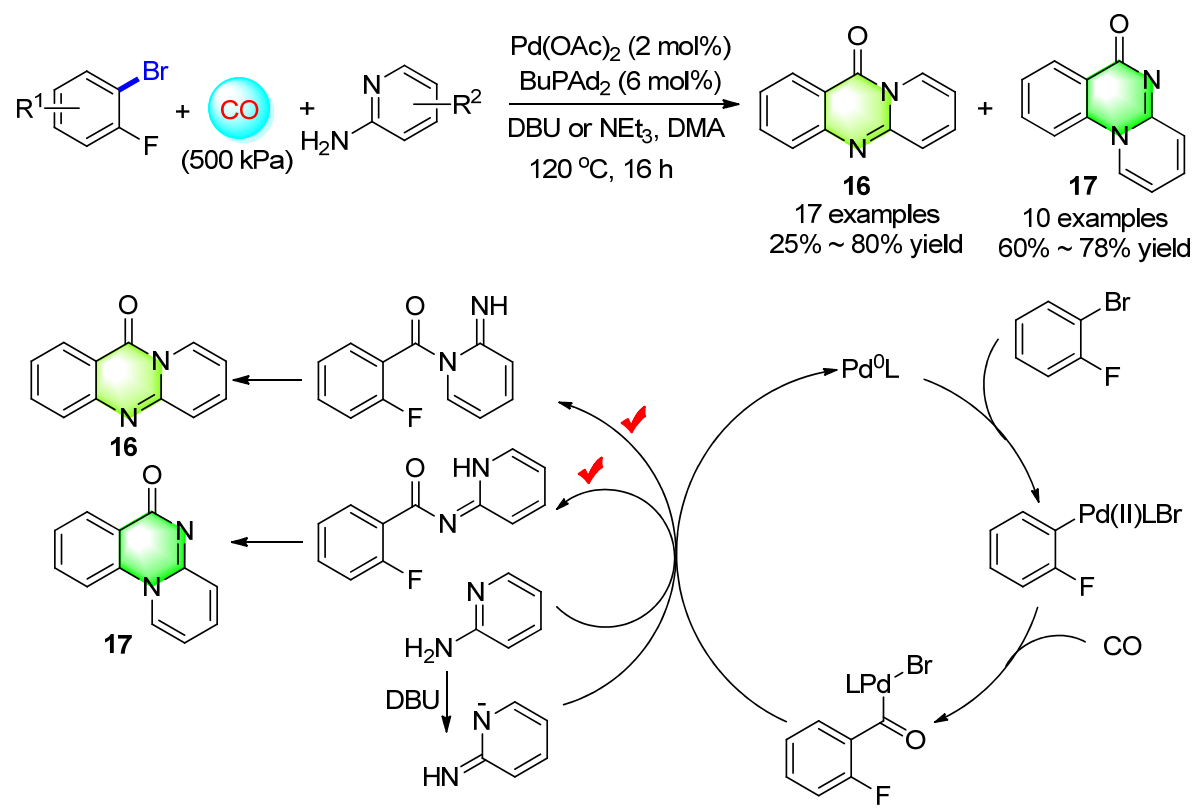

Scheme 11 Synthesis of linear and angular fused quinazolinones

Combining the same substrate 1-bromo-2-fluorobenzenes with amidines under the catalytic palladium system, the corresponding quinazolinones can also be formed in moderate to excellent yields (Scheme 12). Different types of double nucleophiles, such as N-N, N-C, and O-C, can be effectively applied as coupling partners. The corresponding six-membered heterocycles were isolated in moderate to good yields. ${ }^{[17]}$

Continuing to expand the protocols for the synthesis of quinazolinones, an interesting reaction was carried out with 2-aminobenzamides, bromobenzenes, DBU, and $\mathrm{Pd}(\mathrm{OAc})_{2} / \mathrm{BuPAd}_{2}$ in dimethylformamide (DMF) under 1.0 $\mathrm{MPa}$ of $\mathrm{CO}$ at $120{ }^{\circ} \mathrm{C}$. Various substitutes at different positions of bromobenzenes were transformed into the corresponding quinazolinones (Scheme 13). ${ }^{[18]}$ Since the variation of 2-aminobenzamide is very limited, a methodology with widely available substitutes is more attractive and necessary. In 2014, a cascade synthesis of quinazolinones from 2-aminobenzonitriles and aryl bromides via palladium-catalyzed carbonylation reaction was developed

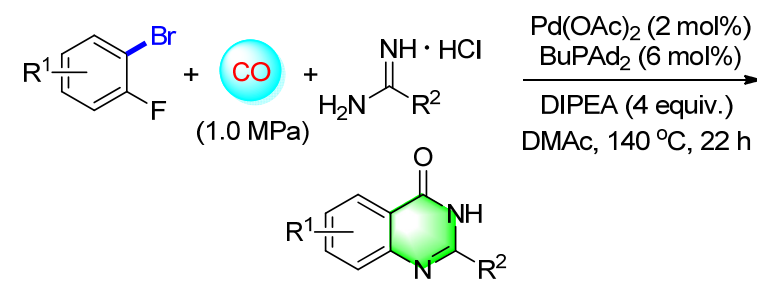<smiles>Cc1nc2ccccc2c(=O)[nH]1</smiles>

Scheme 12 Synthesis of quinazolinones from amidines 


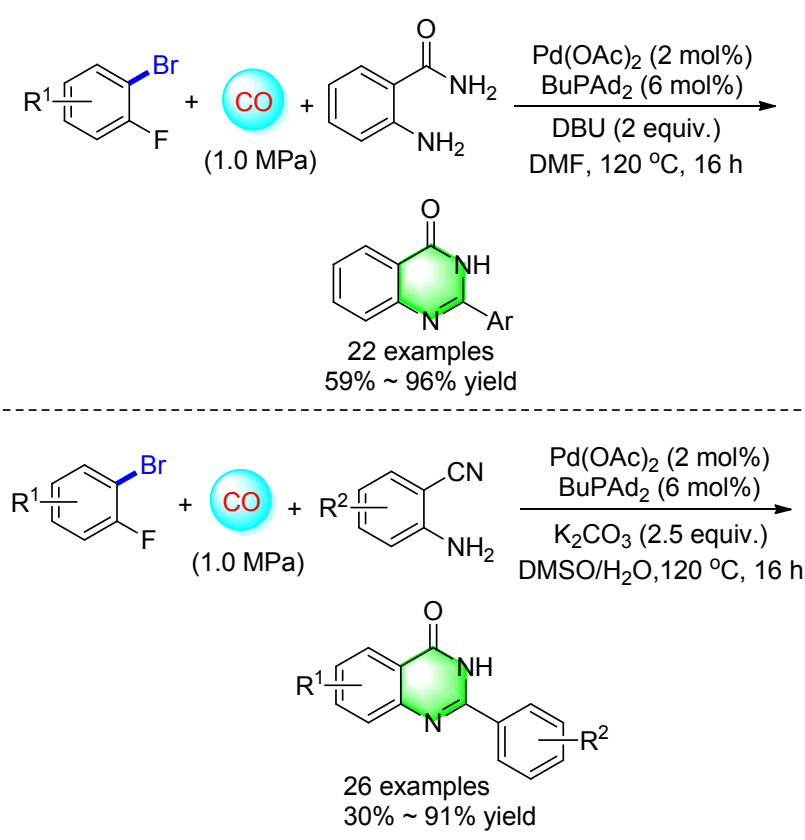

Scheme 13 Synthesis of quinazolinones from aminobenzamides and aminobenzonitriles

in our group. The reactions go through aminocarbonylation of aryl bromides-hydration of nitriles-cyclization sequence. ${ }^{[19]}$

In contrast, starting from commercially available 2-bromoanilines and 2-bromobenzyl amines, with the assistance of a palladium catalyst, isoindolo[1,2-b]quinazolin-10(12H)-ones can be isolated in good yields (Scheme 14). Notably, this procedure proceeded in a highly selective manner and atom economy; two molecules of $\mathrm{CO}$ were incorporated into the substrates selectively. ${ }^{[20]}$

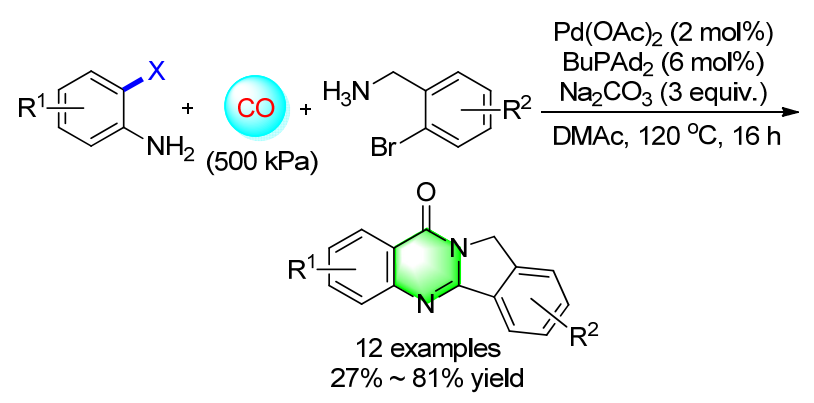

Scheme 14 Synthesis of isoindolo[1,2-b]-quinazolin-10(12H)ones

The reagent capsule was essential to solve problems related to the poisoning of the transition-metal catalyst as well as the compatibility of the various reagents in the one-pot process. An efficient palladium-catalyzed carbonylation method for preparing thiochromenones in a four-component reaction that makes use of a reagent capsule has been developed based on these merits (Scheme 15). With substituted phenylacetylenes and aliphatic alkynes, moderate to good yields of the desired products were achieved. This is the first example of applying a rea- gent capsule for preventing catalyst poisoning and undesired side reactions in a multicomponent reaction. ${ }^{[21]}$

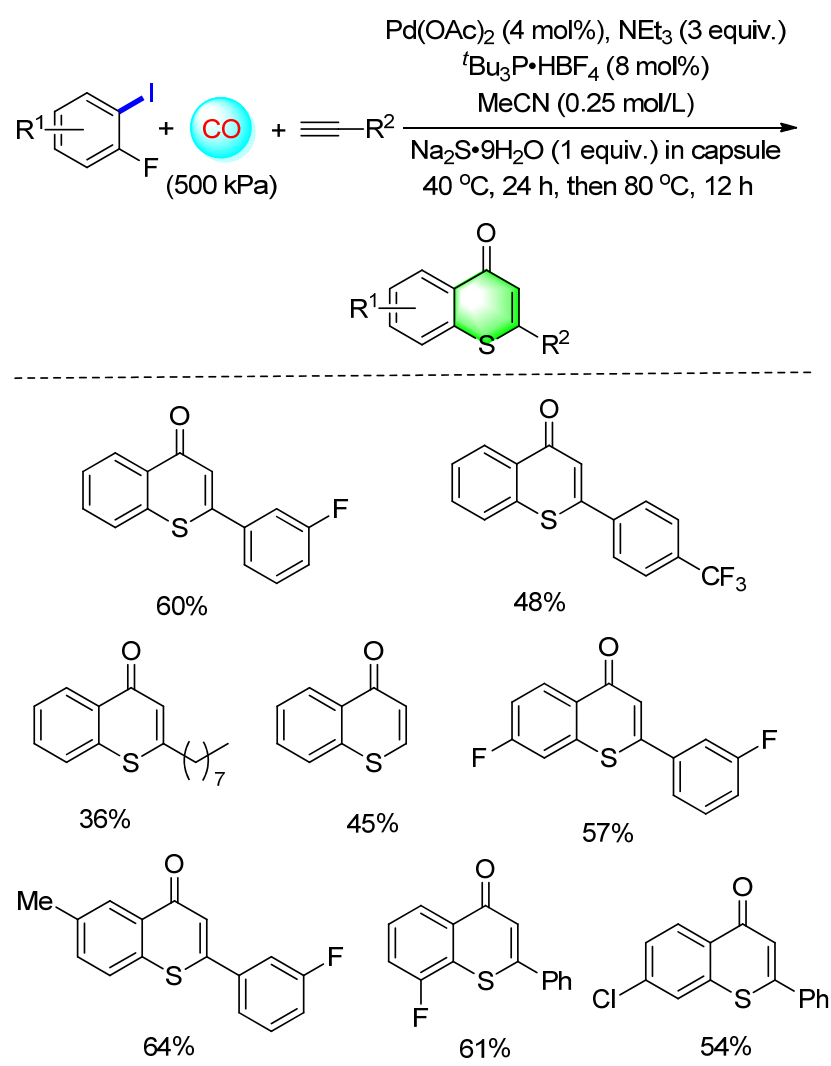

Scheme 15 Synthesis of thiochromenones in four-component reactions

Benzoxazinones represent a class of annulated nitrogen heterocycles that are of interest in organic synthesis due to their various biological activities. By starting from readily available 2-bromoanilines, inexpensive acid anhydrides, $\mathrm{CO}$ and $\mathrm{K}_{2} \mathrm{PdCl}_{4}$ as the catalyst precursor, various 2-alkylbenzoxazinones were synthesized in good yields (Scheme 16). ${ }^{[22]}$

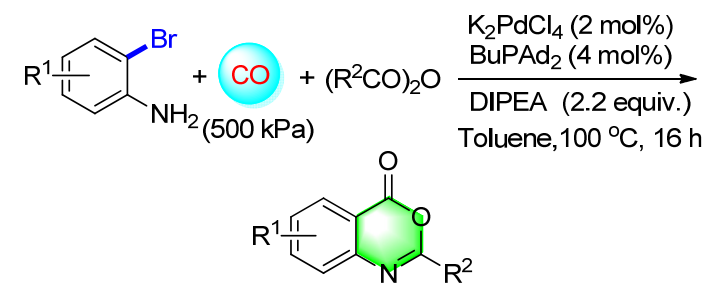<smiles>C/C=C/c1nc2ccccc2c(=O)o1</smiles>

$88 \%$<smiles>O=c1oc(-c2ccccc2)nc2ccccc12</smiles>

$74 \%$
Scheme 16 Synthesis of alkylbenzoxazinones. 
A general and straightforward methodology for the carbonylative synthesis of pharmacologically interesting phthalazinones has been established by using $\mathrm{Pd}(\mathrm{OAc})_{2} /$ DPPF as the catalysts. $\mathrm{MgSO}_{4}$ was used as the additive to facilitate the condensation step in the domino sequence. Starting from readily accessible 2-bromobenz-aldehydes or 2-bromoacetophenone and hydrazines, twenty different phthalazinones were synthesized in moderate to good isolated yields (Scheme 17). ${ }^{[23]}$ When simply changing the hydrazines with 2-bromoanilines, a concise and highly versatile method for the synthesis of functionalized isoindolinones was estabilished. Various 2-bromoanilines undergo palladium-catalyzed carbonylation with 2-formylbenzoic acid under a convenient and mild procedure to give good to excellent yields of the corresponding isoindolinones. ${ }^{[24]}$

$$
\text { (1.0 MPa) }
$$
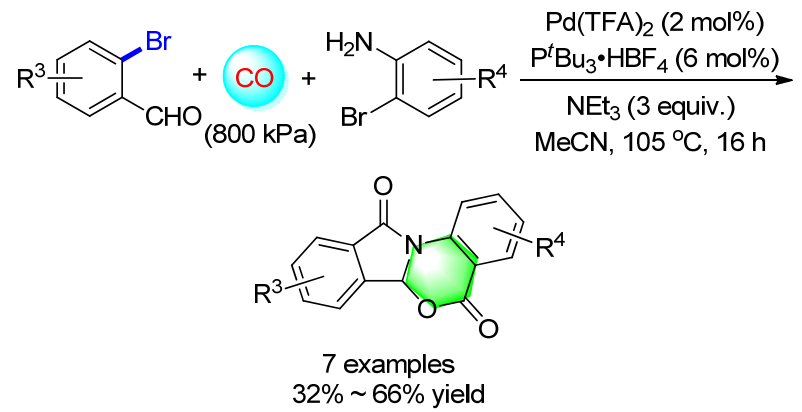

Scheme 17 Synthesis of phthalazinones and isoindolinones

In 2013, our group reported a palladium-catalyzed carbonylative synthesis of coumarins from salicylic aldehydes and benzyl chlorides (Scheme 18). Various coumarins were produced in good to excellent yields. Concerning the reaction pathway, we proposed a palladium catalyzed oxylcarbonylative reaction and followed an intramolecular condensation. ${ }^{[25]}$

Through palladium-catalyzed carbonylative coupling of 2-aminobenzylamine with aryl bromides, we reported an efficient method for the synthesis of quinazolines (Scheme 19). The reactions followed an aminocarbonylationcondensation-oxidation sequence in a one-pot one-step manner. The preliminary investigation showed DMSO serves as both solvent and oxidant in this procedure ${ }^{[26]} \mathrm{By}$ simply changing the electrophile bromobenzene to $o$-dibromo-benzene, an interesting and double carbonylation reaction for the synthesis of isoindoloquinazolinones has been developed. Several kinds of isoindoloquinazolinones

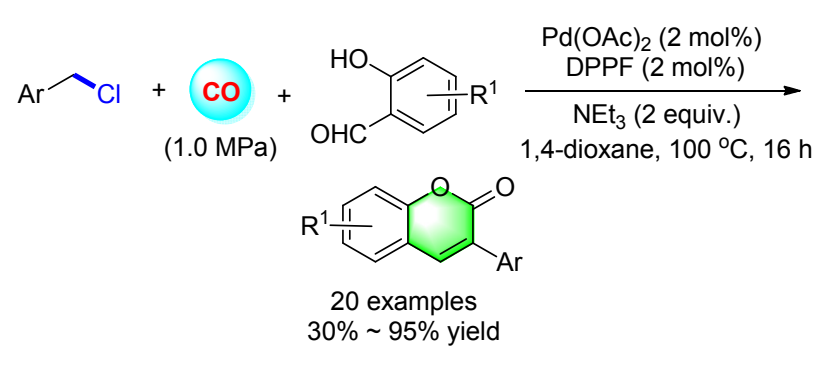<smiles>O=c1oc2ccccc2cc1-c1ccc(Cl)cc1</smiles>

$76 \%$<smiles>O=c1oc2ccc(Cl)cc2cc1-c1ccccc1</smiles>

$95 \%$<smiles>C=Cc1ccc(-c2cc3ccccc3oc2=O)cc1</smiles>

$30 \%$

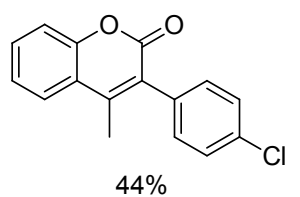

$44 \%$
Scheme 18 Synthesis of coumarins
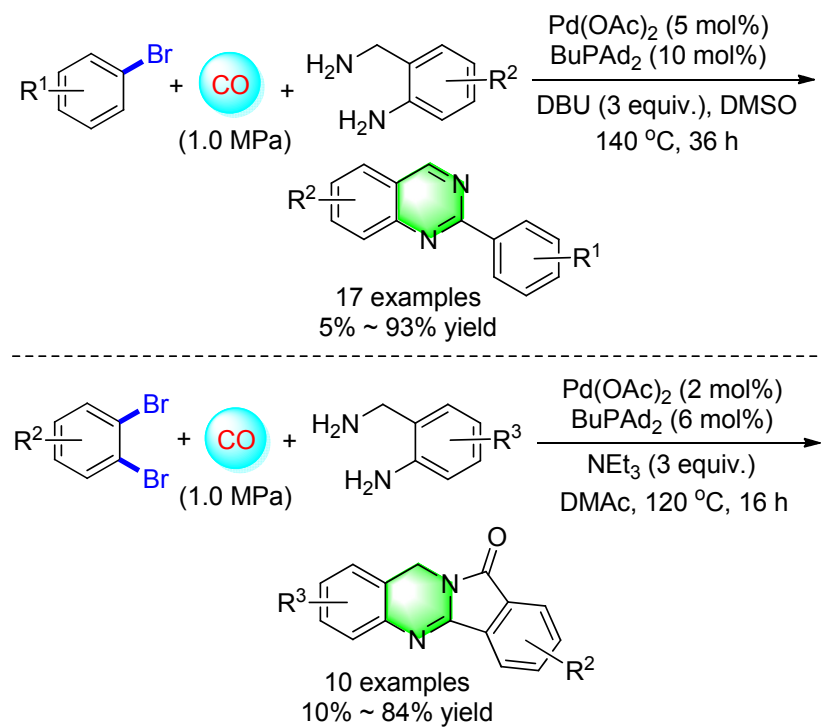

Scheme 19 Carbonylation reactions of aminobenzylamine with bromobenzene or $o$-dibromobenzene

were produced and isolated in moderate to good yields. This procedure enriched the synthesis method of isoindoloquinazolinones and helped in exploring the biological applications of batracylin derivatives. ${ }^{[27]}$

In 2014, a palladium-catalyzed double-carbonylation process for the synthesis of quinazolinediones has been developed (Scheme 20). Starting from commercially available 2-bromobenzonitriles and 2-bromoanilines, a series of isoindolo[1,2-b]quinazoline-10,12-diones were synthesized in a straightforward manner with good isolated yields. At least five different $\mathrm{C}-\mathrm{C}$ and/or $\mathrm{C}-\mathrm{N}$ bonds are selectively formed in this 3-component reaction, which likely proceeds through sequential carbonylation-cyclization-isomerisation-carbonylation steps. ${ }^{[28]}$ 

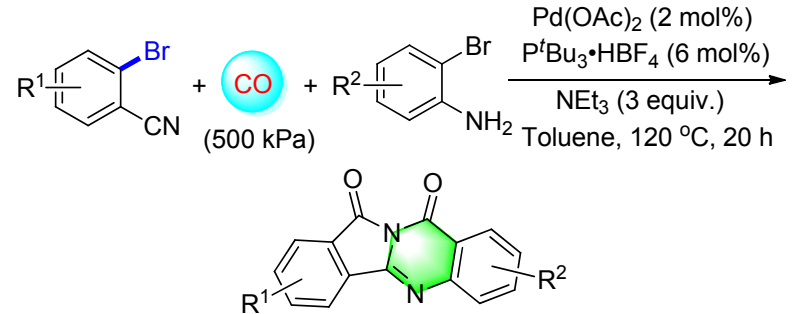

20 examples

$37 \% \sim 88 \%$ yield

Scheme 20 Synthesis of quinazolinediones

\subsection{Synthesis of seven-membered heterocycles} through activation of $\mathrm{C}-\mathrm{X}$ with $\mathrm{CO}$ gas

Seven-membered heterocycles are received continuing attention as their skeletons are widely present in numerous pharmaceuticals and natural products. Among these seven-membered heterocycles, benzoxazepinones represent a class of versatile compounds owing to their promising pharmaceutical and biological activities. Conventional routes to benzoxazepinones and their derivatives usually involve several steps, and isolation of intermediates. In 2015 , our group ${ }^{[29]}$ reported a highly-efficient one-pot palladium-catalyzed amino-carbonylation $/ \mathrm{S}_{\mathrm{N}} \mathrm{Ar}$ approach to dibenzoxazepinones and pyridobenzoxazepinones (Scheme 21). 2-Aminophenol was employed as model substrates to react with 2-bromofluorobenzene or 3-bromo-2-chloropyridine.

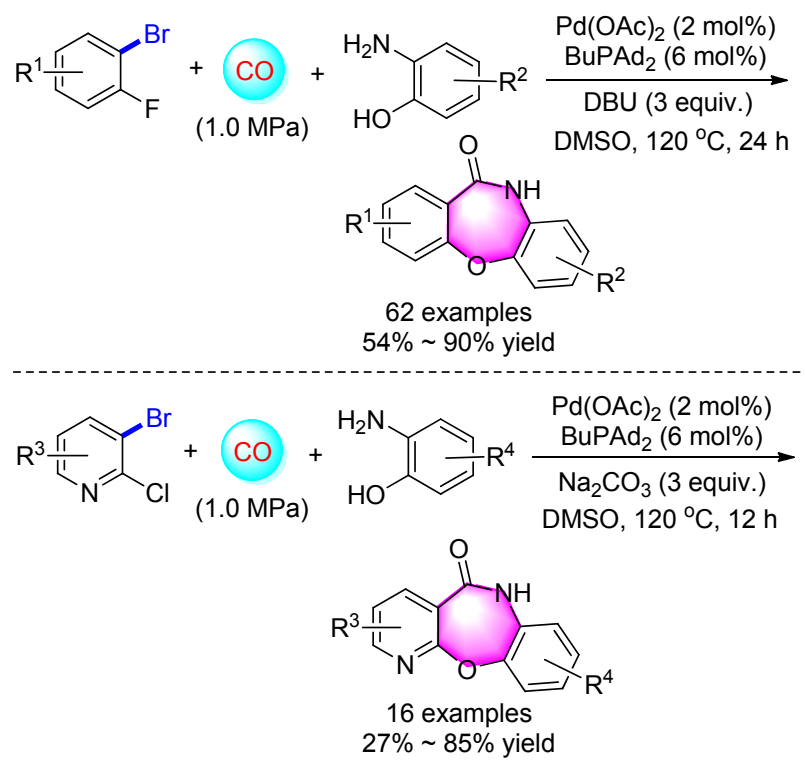

Scheme 21 Carbonylation reactions of 2-aminophenols with 2-bromofluorobenzenes or 3-bromo-2-chloropyridines

A cascade procedure for the synthesis of 2,3-dihydrobenzodioxepinone from 2-bromophenols and epoxides was estabilished as well. Starting from commercially available substrates, moderate to good yields of versatile desired products were obtained in a good regioselectivity (major product $>90 \%$ ) under mild conditions (Scheme 22). The reactions went through nucleophilic ring-opening of epoxides and subsequent palladium-catalyzed intramolecular alkoxylcarbonylation. ${ }^{[30]}$

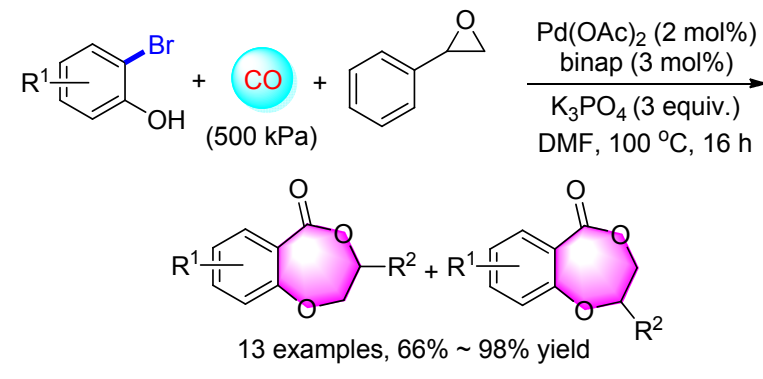<smiles>O=C1OC(c2ccccc2)COc2ccccc21</smiles><smiles>O=C1OC2CCCC2Oc2ccccc21</smiles>

$70 \%$ yield, $r r>99: 1$
$90 \%$ yield, $r r=90: 10$<smiles>CC(C)C1COc2ccccc2C1=O</smiles><smiles>O=C1OC(c2ccccc2)COc2cc3ccccc3cc21</smiles>

$85 \%$ yield, $r r=90: 10$
Scheme 22 Synthesis of benzodioxepinone

\section{Synthesis of heterocycles through ac- tivation of $\mathrm{C}-\mathrm{H}$ with $\mathrm{CO}$ gas}

Among all the heterocycles, quinolin-2(1H)-ones are an important class of natural products with a wide range of biological activities, such as anticancer, antibacterial, antiviral, antibiotic activity and so on. Additionally, quinolin$2(1 H)$-ones have also been used as valuable synthetic intermediates in organic synthesis. In 2016, a novel and efficient iridium-catalyzed carbonylative annulation of simple anilines with internal alkynes for the straightforward synthesis of halogen-containing quinolin-2 $(1 H)$-ones was developed (Scheme 23). The reaction proceeds without pre-activation and directing groups through direct $\mathrm{N}-\mathrm{H}$ and $\mathrm{C}-\mathrm{H}$ bond activation with a broad substrate scope, high efficiency, and excellent selectivity. Remarkably, halogen functional groups can be well tolerated here, and this is the first example of iridium-catalyzed carbonylative $\mathrm{C}-\mathrm{H}$ activation of anilines. ${ }^{[31]}$ The first step is the oxidation of $\operatorname{Ir}^{\mathrm{I}}$ to $\operatorname{Ir}^{\mathrm{III}}$ which then get ready for the catalytic cycle. Then, a nitrogen bonded iridium complex will be formed after ligand exchange with aniline derivative which will produce iridium formamide intermediate after $\mathrm{CO}$ insertion. A five-membered iridium cycle through ortho $\mathrm{C}-\mathrm{H}$ bond activation will be produced from the iridium formamide complex. After the insertion of internal alkyne, seven-membered iridium cycle will be formed which then give the final quinolin-2(1H)-ones after reductive elimination and the together formed $\operatorname{Ir}^{\mathrm{I}}$ will be reoxidized into $\operatorname{Ir}^{\mathrm{III}}$ by copper salt. 

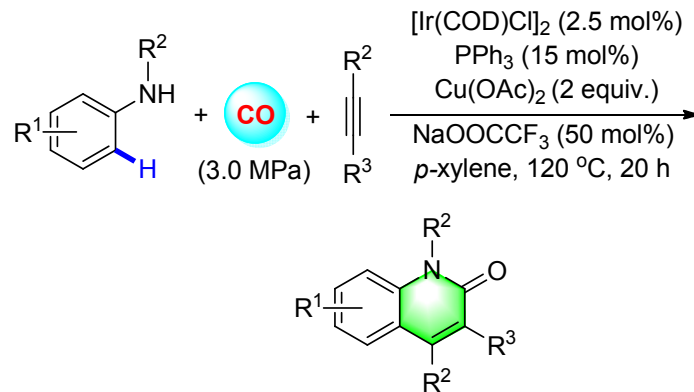

22 examples

$31 \% \sim 93 \%$ yield<smiles>Cn1c(=O)c(-c2ccccc2)c(-c2ccccc2)c2ccccc21</smiles>

$61 \%$<smiles>CCc1c(CC)c2ccccc2n(C)c1=O</smiles>

$93 \%$<smiles></smiles>

$71 \%$<smiles></smiles>
$68 \%$<smiles>Cc1c(-c2ccccc2)c2ccccc2n(C)c1=O</smiles>

$67 \%$

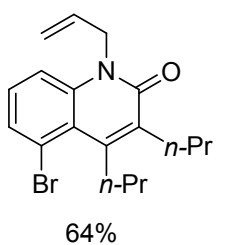<smiles>CCCPc1c([Te])c2c(Br)ccc3c2n(c1=O)CCC3</smiles>

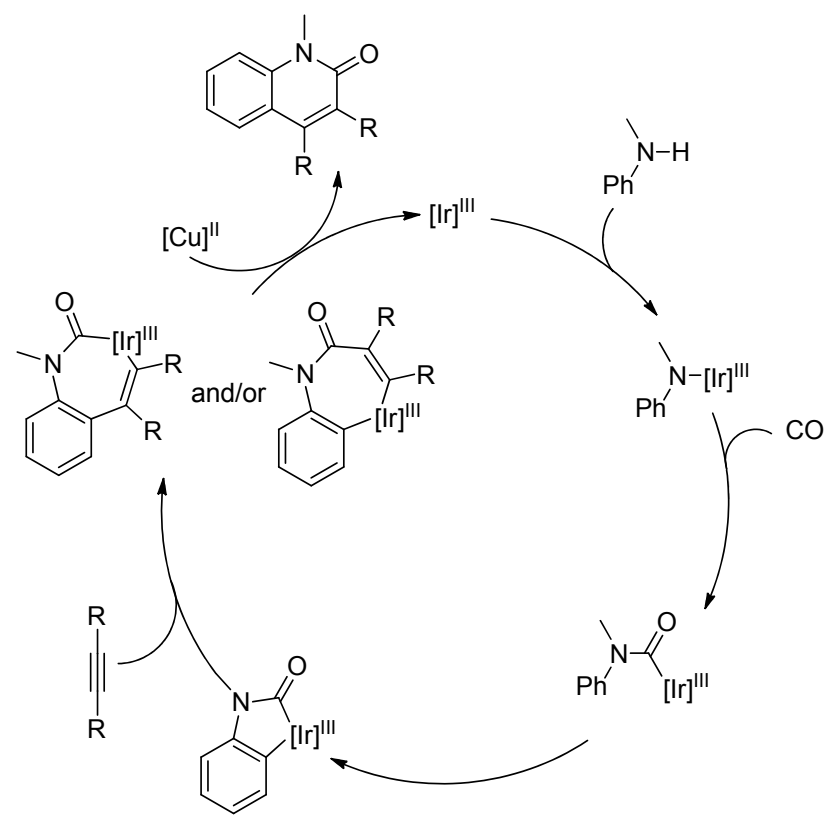

Scheme 23 Synthesis of benzodioxepinone

Inspired by this positive result, we also expand the iridium-catalyzed carbonylation reactions. In 2016, the first carbonylative annulation reaction for the direct synthesis of coumarins from phenols and alkynes was reported (Scheme 24). With iridium as the catalyst and copper as the promotor, various coumarins were prepared in good to excellent yields and with good selectivity at atmospheric pressure. Interestingly, when $\mathrm{AcOH}$ and bis(2-methoxyphenyl)(phenyl)phosphane were used, the isomer product flavones was got. Various flavones were also isolated in moderate to good yields with excellent regioselectivity and functional group tolerance by using the iridium catalyst system. This is the first example of direct carbonylation annulation of non-preactivated phenols and alkynes to produce flavones, with the choice of ligand proving to be critical for the success of this transformation. ${ }^{[32]}$ More recently, with palladium as the catalyst, the carbonylative cyclization of terminal alkynes with phenols was realized as well. ${ }^{[32 \mathrm{c}]}$

\section{Synthesis of heterocycles through ac- tivation of $\mathbf{C}-\mathrm{X}$ with $\mathrm{CO}$ surrogates}

\section{$4.1 \mathrm{Mo}(\mathrm{CO})_{6}$ as $\mathrm{CO}$ surrogate}

Since the highly toxic and flammable properties of carbon monoxide, performing carbonylation reactions without the use of $\mathrm{CO}$ are highly desired and will contribute to the further improvement of sustainable chemistry. Among the candidates, $\mathrm{Mo}(\mathrm{CO})_{6}$ as an air-stable and non-toxic solid is an attractive $\mathrm{CO}$ source. Therefore, a general and convenient methodology for 2-amino benzoxazinone synthesis using 2-bromoanilines and isocyanates as substrates and $\mathrm{Mo}(\mathrm{CO})_{6}$ as a solid $\mathrm{CO}$ surrogate was developed (Scheme 25). This reaction can tolerate both electron-donating and electron-withdrawing groups and give the corresponding benzoxazinones up to $90 \%$ yield. Remarkably, 3-phenylquinazoline-2,4(1H,3H)dione as one of the most possible products is not detected in this transformation. We propose that $\mathrm{Mo}(\mathrm{CO})_{6}$ may act as a Lewis acid and coordinate with 20 to assist in the formation of 2-aminobenzoxazinones. ${ }^{[33]}$

With $\mathrm{Mo}(\mathrm{CO})_{6}$ as a solid $\mathrm{CO}$ surrogate, a novel and convenient way to synthesize $N$-phenylquinazolinones through aminocarbonylation of 2-aminobenzonitriles with bromoarenes was developed (Scheme 26). Aryl bromides and 2-aminobenzonitrile derivatives were selected as the substrates, various quinazolinones can be formed by the assistance of urea hydroperoxide (UHP) in $25 \% \sim 76 \%$ yields of two steps. ${ }^{[34]}$ Later on, a procedure for palladium-catalyzed carbonylation synthesis of quinazolinones from 2-bromoformanilides and nitro compounds in $41 \%$ $97 \%$ yields was also reported. Selective reduction of the nitro group in the presence of other sensitive competing functionalities was a challenging problem, and the compatibility between the conditions of nitro reduction and aminocarbonylation was hard to be achieved. In this transformation, both aromatic nitros and aliphatic nitros were found to be suitable substrates. Moreover, $\mathrm{Mo}(\mathrm{CO})_{6}$ was not only a $\mathrm{CO}$ source but also a nitro compound reducing reagent and a cyclization promoter. ${ }^{[35]}$ 
I $\quad\left[\operatorname{lr}(\mathrm{COD}) \mathrm{Cl}_{2}(2.5 \mathrm{~mol} \%)\right.$

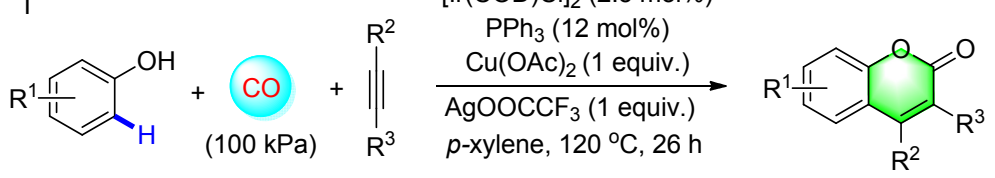

23 examples

$59 \% \sim 83 \%$ yield
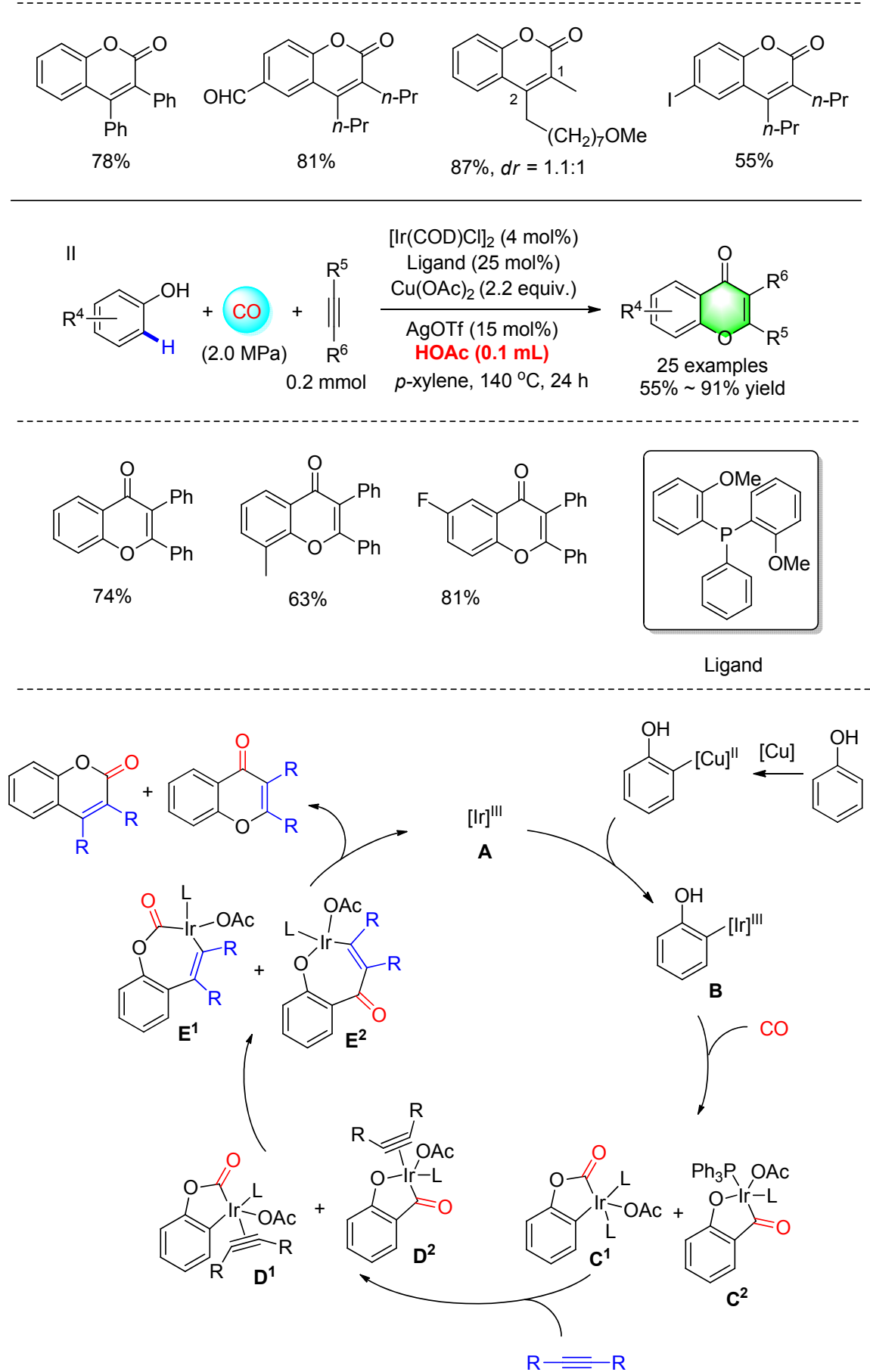

Scheme 24 Iridium catalyzed the synthesis of coumarins and flavones

$N$-Substituted phthalimides represented an important class of biologically active molecules. Regarding their importance, a palladium-catalyzed carbonylation synthesis of phthalimides from 1,2-dibromoarenes with $\mathrm{Mo}(\mathrm{CO})_{6}$ was demonstrated (Scheme 27). The reaction tolerated various functional groups on the aromatic rings and gave the corresponding phthalimides up to $84 \%$ yield. ${ }^{[36]}$ 


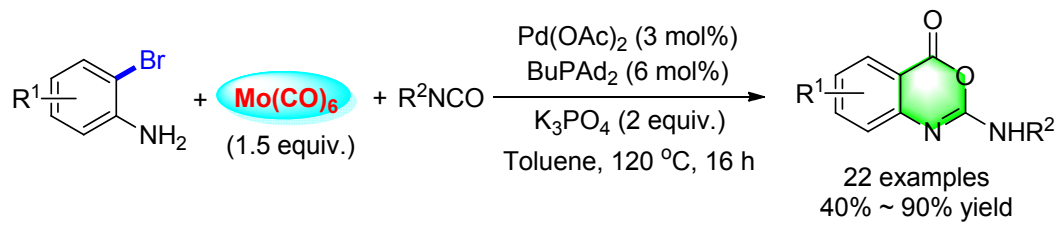

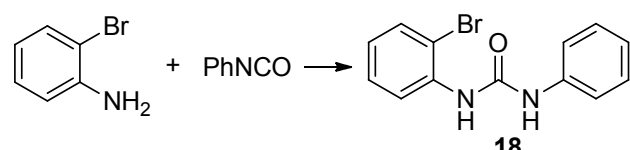

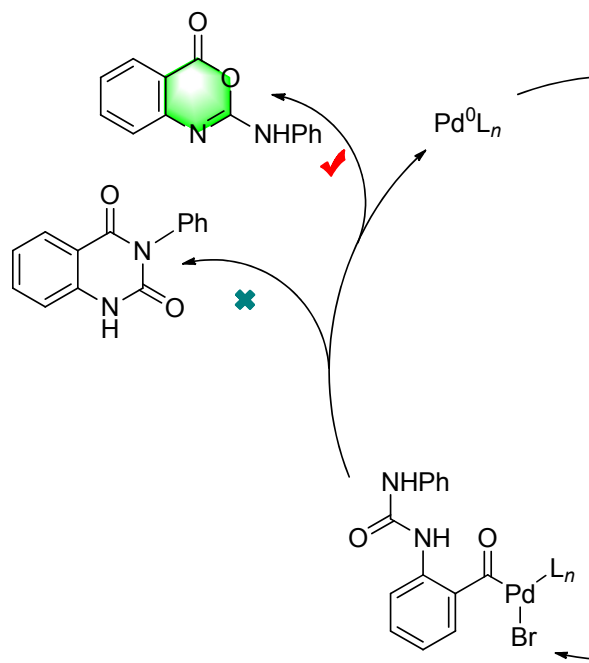

18

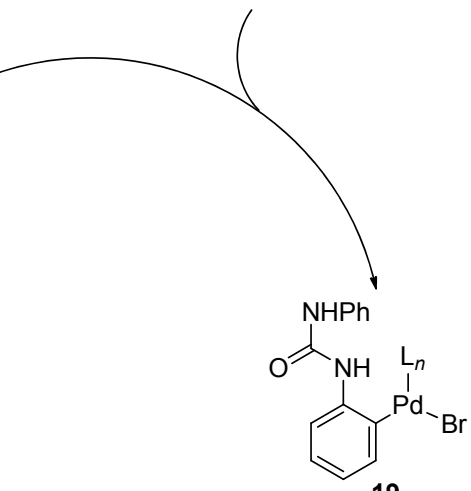

20

CO

Scheme 25 Synthesis of benzoxazinone by using $\mathrm{Mo}(\mathrm{CO})_{6}$.
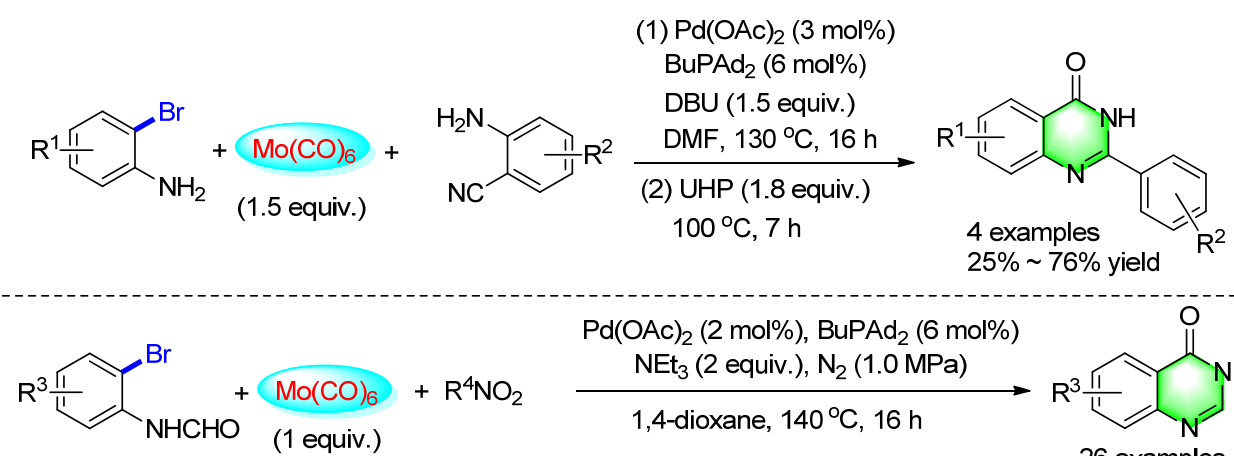

$\mathrm{Pd}(\mathrm{OAc})_{2}(2 \mathrm{~mol} \%), \mathrm{BuPAd}_{2}(6 \mathrm{~mol} \%)$ $\mathrm{NEt}_{3}$ (2 equiv.), $\mathrm{N}_{2}(1.0 \mathrm{MPa})$

1,4-dioxane, $140^{\circ} \mathrm{C}, 16 \mathrm{~h}$

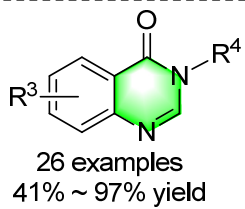

Scheme 26 Synthesis of quinazolinones by using $\mathrm{Mo}(\mathrm{CO})_{6}$

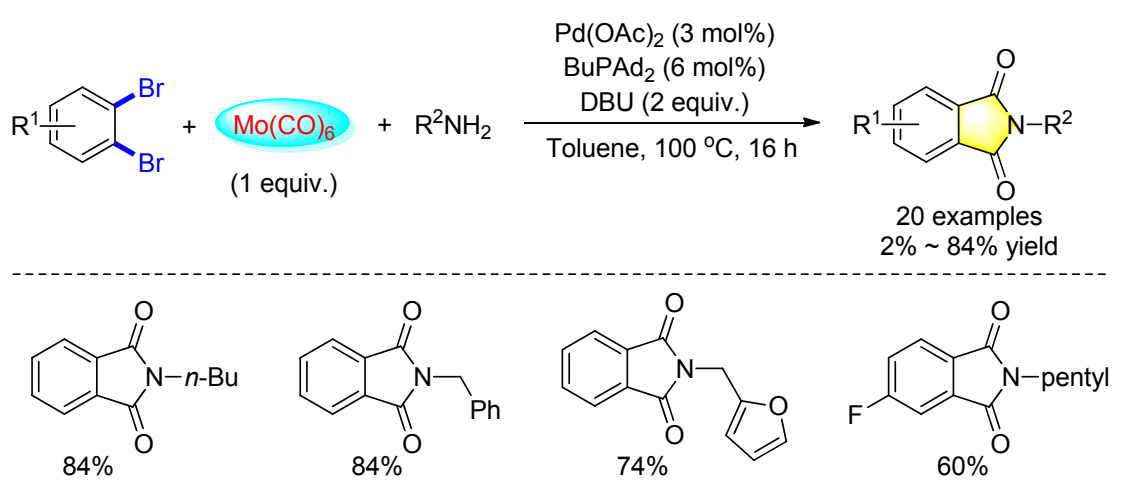

Scheme 27 Synthesis of phthalimides by using $\mathrm{Mo}(\mathrm{CO})_{6}$ 
Indoles were important skeletons in material science and pharmaceuticals. Recently, a variety of methodologies have been published. Our group ${ }^{[37]}$ has elaborated a versatile method to form different kinds of N-benzoylindoles via palladium-catalyzed aminocarbonylation of aryl bromides with $\mathrm{Mo}(\mathrm{CO})_{6}$ (Scheme 28). In this reaction, DBU was used as the base due to its ability to coordinate at the molybdenum to promote the in situ release of $\mathrm{CO} . \mathrm{K}_{3} \mathrm{PO}_{4}$ can increase the yield of the reaction as a base.

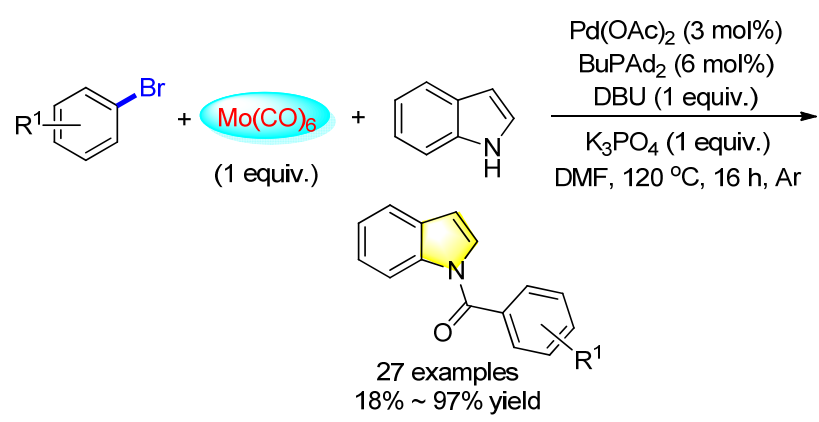

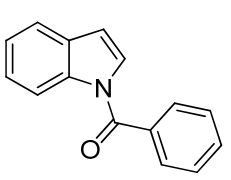

$89 \%$
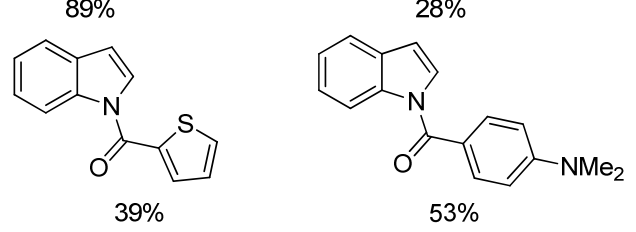

Scheme 28 Synthesis of $N$-benzoylindoles by using $\operatorname{Mo}(\mathrm{CO})_{6}$

\subsection{Formic acid as a CO surrogate}

Formic acid represents an interesting and potential bio-renewable compound that can act as a carbon monoxide precursor for the production of value-added chemicals. With formic acid as the $\mathrm{CO}$ source and $\mathrm{Ac}_{2} \mathrm{O}$ as the activator, a novel method for the synthesis of a variety of 2-benzylideneindolin-3-ones was reported (Scheme 29). A plausible reaction mechanism was proposed, a palladium catalyzed carbonylation reaction of 2-iodoanilines and alkynes gave the alkynyl ketone intermediate, which formed the final product 2-benzylideneindolin-3-ones through a ring closing reaction with the assistance of $\mathrm{PPh}_{3}$. Furthermore, using the same condition, different 2-iodophenols and terminal alkynes transformed into the corresponding aurones in moderate to good yield. ${ }^{[38]}$

\subsection{Miscellaneous}

Compared to many other CO surrogates, paraformaldehyde is more desirable since it is a solid, cheap, stable, easily-to-handle and exhibits low toxicity. In 2014, our group established a simple and general method for the synthesis of benzoxazinone derivatives from $\mathrm{N}$-(o-bromoaryl)amides and paraformaldehyde (Scheme 30). The starting materials can be easily prepared from 2-bromoanilines and acid chlorides or anhydrides. This method

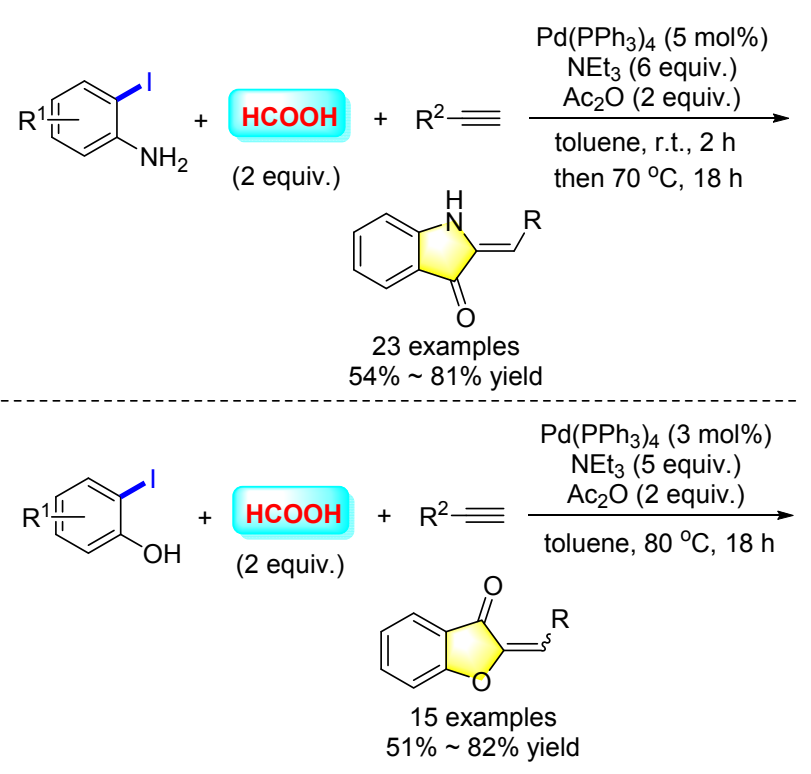

Scheme 29 Synthesis of 2-benzylideneindolin-3-ones and aurones by using formic acid

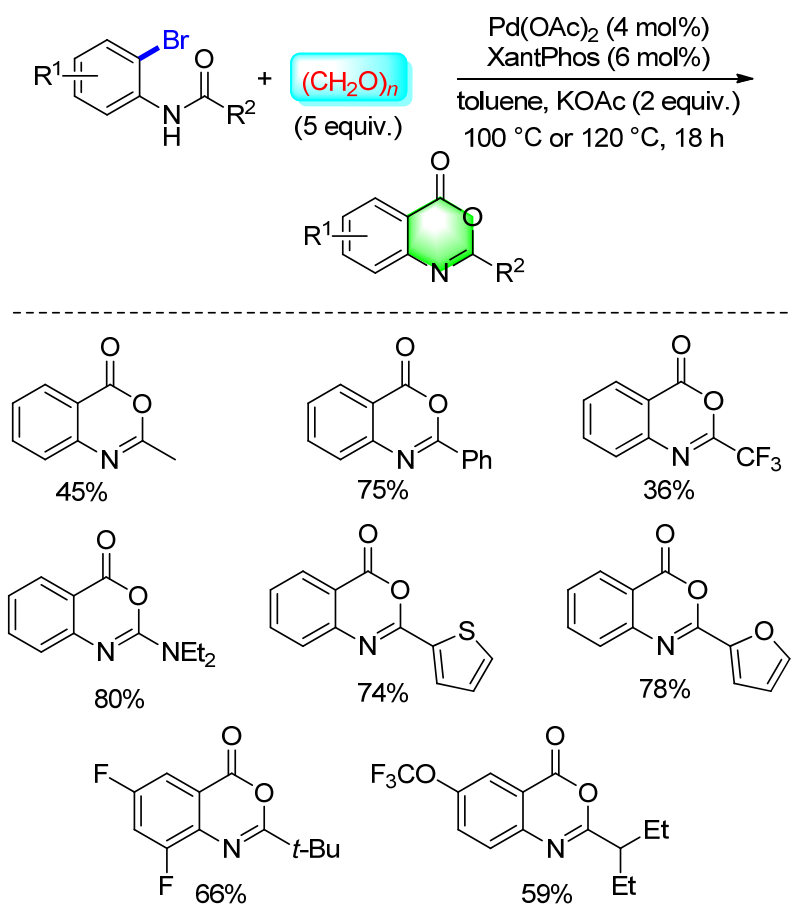

Scheme 30 Synthesis of benzoxazinones by using paraformaldehyde

provided a practical pathway for the carbonylation synthesis of various benzoxazinone heterocycles in moderate to good yields. ${ }^{[39]}$

\section{Synthesis of heterocycles through ac- tivation of $\mathrm{C}-\mathrm{H}$ with $\mathrm{CO}$ surrogates}

\section{$5.1 \mathrm{Mo}(\mathrm{CO})_{6}$ as a $\mathrm{CO}$ surrogate}

The transition-metal-catalyzed direct functionalization of inert $\mathrm{C}-\mathrm{H}$ bonds for the synthesis of complex molecules matched well with the concept of sustainable development as it avoids tedious and sluggish pre-activations. In 
2014, a novel procedure for the synthesis of highly substituted 2-quinolinones by carbonylation cyclization of $\mathrm{N}$-aryl-pyridine-2-amines and internal alkynes through $\mathrm{C}$ $\mathrm{H}$ activation was reported. $\mathrm{Mo}(\mathrm{CO})_{6}$ was applied as a solid $\mathrm{CO}$ source, the reaction proceeded in an atom economic manner, and various 2-quinolinone derivatives were prepared in moderate to good yields. ${ }^{[40]}$ When we chose norbornene as the coupling partner, an interesting transformation on palladium-catalyzed carbonylative $\mathrm{C}-\mathrm{H}$ activation of arenes with norbornene has been developed. Various 5-(pyridin-2-yl)-hexahydro-7,10-methanophenanthridin-6(5H)-ones were produced in moderate yields. The product can also be oxidized to the corresponding 5(pyridin-2-yl)-tetrahydro-7,10-methanophenanthridin$6(5 H)$-one by using 2,3-dichloro-5,6-dicyano- $p$-benzoquinone (DDQ) as the oxidant (Scheme 31). ${ }^{[41]}$

Apart from using $\mathrm{N}$-aryl-pyridine-2-amines as the di- recting group, we also tested other directing groups for the functionalization or synthesis of the heterocycles. For example, in 2016, a general palladium-catalyzed carbonylation transformation of the $\mathrm{C}-\mathrm{H}$ bond on aromatic rings to produce esters by using 2-arylpyridine derivatives as the substrates was reported (Scheme 32). Good yields of the corresponding products have been obtained with wide functional group tolerance and excellent regioselectivity. A variety of aliphatic alcohols are suitable reactants here. ${ }^{[42]}$

Furthermore, two interesting palladium-catalyzed carbonylation protocols for the intramolecular cyclization of azoarenes and ketimines were also established. With $\mathrm{Mo}(\mathrm{CO})_{6}$ as the solid $\mathrm{CO}$ source and through $\mathrm{C}\left(\mathrm{sp}^{2}\right)-\mathrm{H}$ bond activation, a series of azoarenes and ketimines were transformed into the corresponding 2-aryl-indazolones and 3 -methyleneisoindolin-1-ones in moderate to good yields (Scheme 33). ${ }^{[43]}$
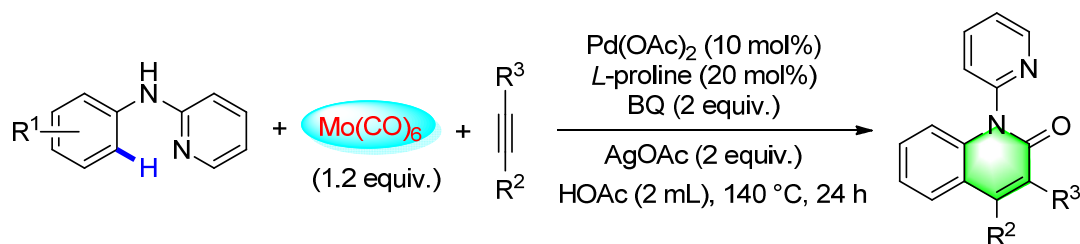

examples

$13 \% \sim 80 \%$ yield

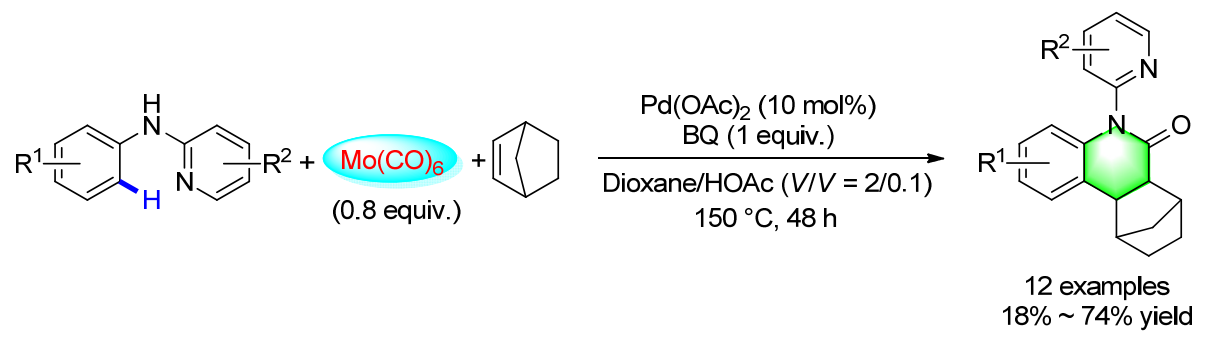

Scheme 31 Synthesis of quinolinone derivatives
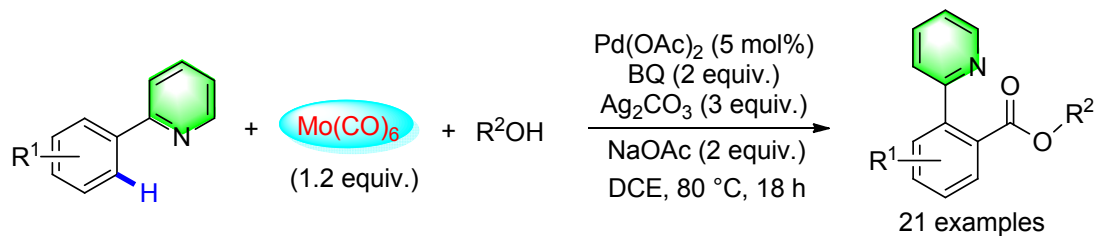
$40 \% \sim 80 \%$ yield<smiles>COC(=O)c1cccc(Cl)c1-c1ncccn1</smiles><smiles>CC(C)OC(=O)c1ccccc1-c1ccccn1</smiles><smiles>CC(C)(C)OC(=O)c1ccccc1-c1ccccn1</smiles><smiles>COC(=O)c1ccccc1-c1ccccn1</smiles><smiles>COC(=O)c1ccsc1-c1ccccn1</smiles><smiles>COC(=O)c1cccc2ccc3cccnc3c12</smiles><smiles>COC(=O)c1ccccc1/N=N/c1ccccc1</smiles><smiles>COC(=O)c1ccccc1-n1cccn1</smiles>

$61 \%$

Scheme 32 Functionalization of 2-arylpyridine 


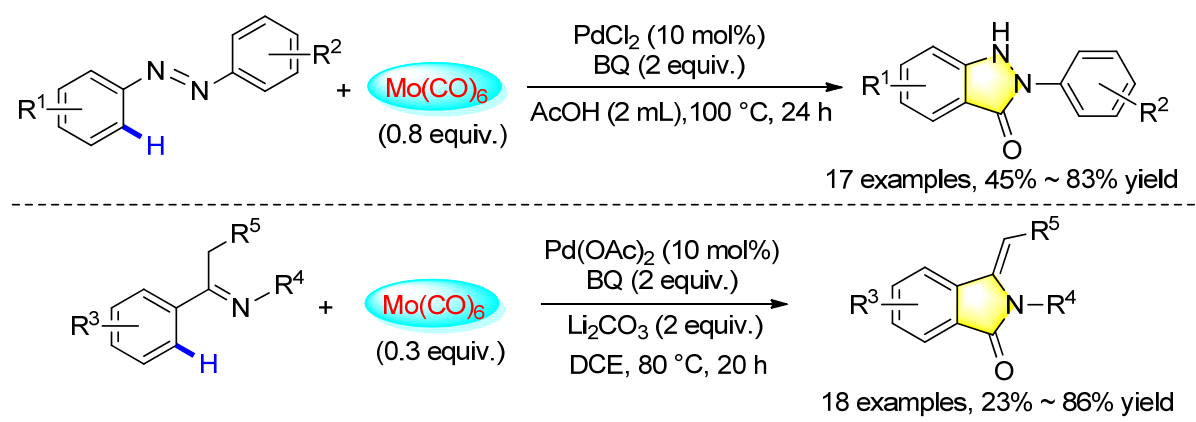

Scheme 33 Synthesis of 2-arylindazolones and 3-methyleneisoindolin-1-ones

Among the various noble transition-metal catalysts, ruthenium catalysts are attractive due to their relative low cost and high reaction selectivity. Several challenging transformations have been realized with ruthenium complex as the catalyst, however, the reports about ruthenium catalyzed carbonylation reactions are still very limited. In 2017, our group developed a convenient procedure for the synthesis of 3-acylindoles from simple indoles and aryl iodides. Through ruthenium-catalyzed carbonylative $\mathrm{C}-\mathrm{H}$ functionalization of indoles, with $\mathrm{Mo}(\mathrm{CO})_{6}$ as the solid $\mathrm{CO}$ source, the desired indol-3-yl aryl ketones were isolated in moderate to good yields. Not only $\mathrm{N}$-alkyl indoles but also $\mathrm{N}-\mathrm{H}$ indoles can be applied in this reaction (Scheme 34). ${ }^{[4]}$
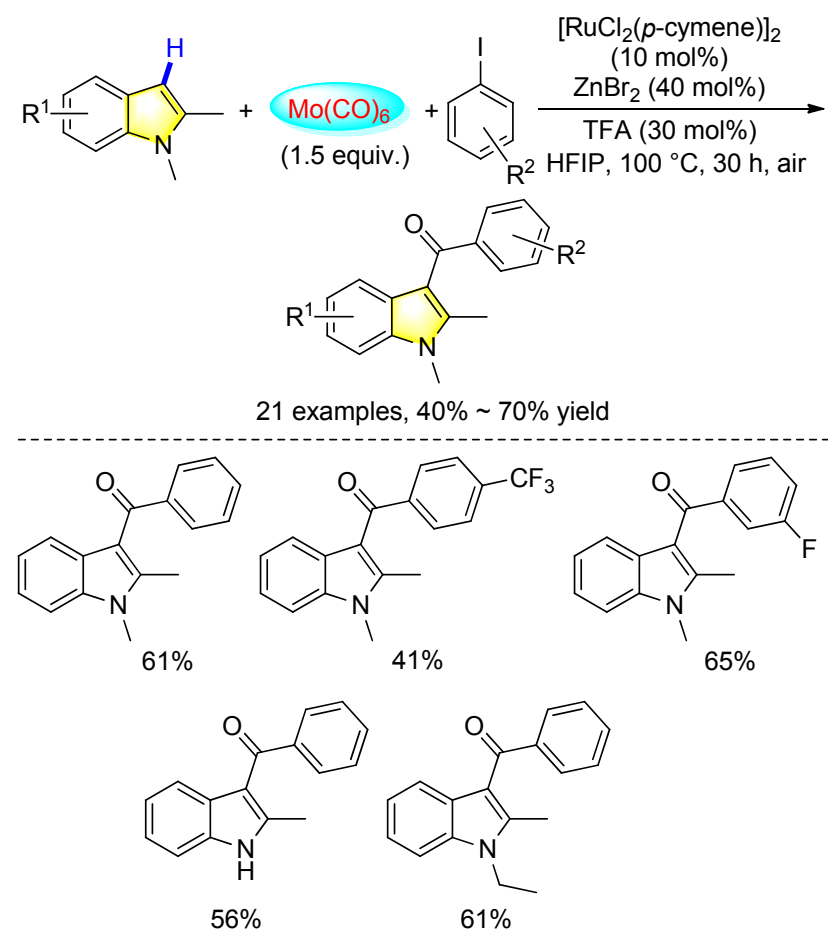

Scheme 34 Ruthenium-catalyzed functionalization of indoles

\subsection{Formic acid as a $\mathrm{CO}$ surrogate}

Benzofuranones and isobenzofuranones are very important structural moieties which present in numerous pharmaceutical compounds and biological molecules. Thus the development of new synthetic methods for such moieties is always under demand. In 2016, a convenient palla- dium-catalyzed carbonylation synthesis of benzofuran-2(3H)-ones by using commercially available phenols and aldehydes as the substrates with formic acid as the $\mathrm{CO}$ precursor was reported, and benzofuran-2(3H)-ones have been prepared in moderate to good yields. Both aromatic and aliphatic aldehydes are applicable in this reaction (Scheme 35). ${ }^{[45]}$

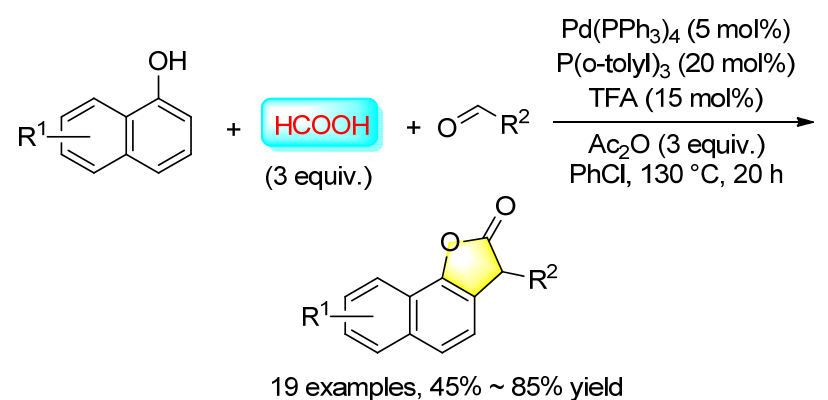

Scheme 35 Synthesis of benzofuran-2(3H)-ones

\subsection{Miscellaneous}

Among all the possible CO candidates, DMF is an attractive one because it is cheap and easily accessible. The first general palladium-catalyzed carbonylation cyclization of $\mathrm{N}$-arylpyridin-2-amines by $\mathrm{C}-\mathrm{H}$ activation using $\mathrm{DMF}$ as the $\mathrm{CO}$ surrogate was developed. Various quinazolinones were formed in moderate to good yields with good functional group tolerance. A ${ }^{13} \mathrm{CO}$-labelled DMF study and other control experiments indicated that the carbonyl group of DMF is the $\mathrm{CO}$ source in this methodology. The kinetic isotope effect (KIE) value suggested that the $\mathrm{C}-\mathrm{H}$ activation step might not be involved in the rate-determining step under our conditions. ${ }^{[46]}$ Meanwhile, the heterogeneous catalyst $\mathrm{Pd} / \mathrm{C}$ was also applicable in this reaction (Scheme 36). ${ }^{[4]}$

Hexaketocyclohexane octahydrate $\left(\mathrm{C}_{6} \mathrm{O}_{6} \cdot 8 \mathrm{H}_{2} \mathrm{O}\right)$ is a kind of nontoxic stable solid. It was originally produced by oligomerization of carbon monoxide, and can be considered to be six-fold of carbon monoxide with almost $100 \%$ atom efficiency. Because the ring of hexaketocyclohexane is highly strained, it can potentially decompose to $\mathrm{CO}$ in the reaction solution. Very recently, our group developed a novel procedure on copper-catalyzed double carbonylation of indoles with alcohols via $\mathrm{C}-\mathrm{H}$ bond functionalization (Scheme 37). ${ }^{[48]}$ Using alcohols as reaction partners, 


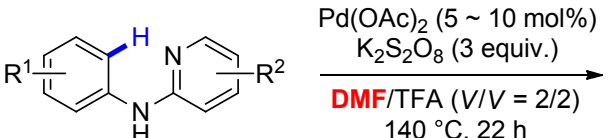

$$
\begin{aligned}
& \text { 事 } \\
& 19 \text { examples, } 23 \% \sim 93 \% \text { yield }
\end{aligned}
$$

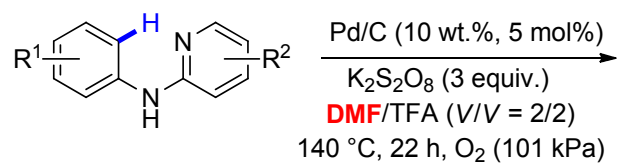

$$
\begin{aligned}
& \text { 事 } \\
& 15 \text { examples, } 21 \% \sim 71 \% \text { yield }
\end{aligned}
$$

Scheme 36 Synthesis of quinazolinones by using DMF

moderate to good yields of the desired double carbonylation products have been obtained. Wide functional group tolerance and substrate scope can be observed.

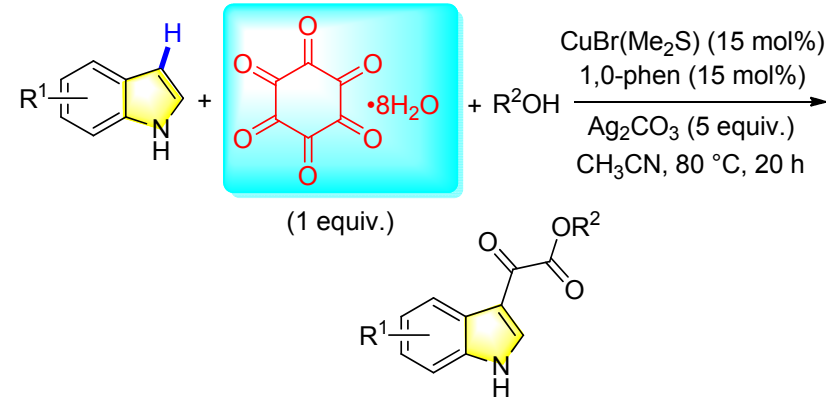<smiles>COC(=O)C(=O)c1c[nH]c2ccccc12</smiles><smiles>CC(C)OC(=O)C(=O)c1c[nH]c2ccccc12</smiles><smiles></smiles><smiles>COC(=O)C(=O)c1c[nH]c2cccc(Br)c12</smiles><smiles>COC(=O)C(=O)c1c(-c2ccccc2)[nH]c2ccccc12</smiles><smiles>COC(=O)C(=O)c1c(C)n(C)c2ccccc12</smiles><smiles>COC(=O)C(=O)c1c[nH]c2ccc(F)cc12</smiles>

Scheme 37 Double carbonylation of indoles by using $\mathrm{C}_{6} \mathrm{O}_{6}$

Benzene-1,3,5-triyl triformate (TFBen) is a stable and non-reacting CO surrogate was developed in our group. ${ }^{\text {[49] }}$ Recently, we achieved a CO gas-free palladium-catalyzed carbonylative procedure for the synthesis of bis(indolyl)methanes. ${ }^{[50]}$ With TFBen as the solid CO source, aryl iodides and indoles were transformed into the corresponding bis(indolyl)methane derivatives in moderate to excellent yields (Scheme 38). Based on our mechanistic studies,

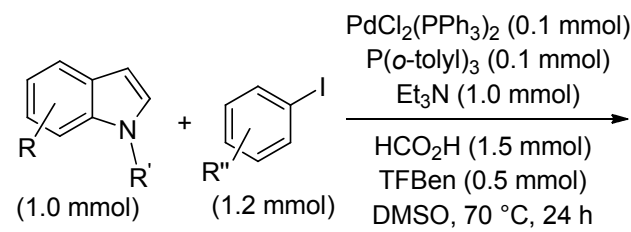<smiles>[R]C=Cc1ccccc1-n1cccc1C=C</smiles><smiles>[R]c1ccccc1C(c1cn([R])c2ccccc12)c1cn([Z])c2ccccc12</smiles><smiles>c1ccc(C(c2c[nH]c3ccccc23)c2c[nH]c3ccccc23)cc1</smiles><smiles>Cc1ccc2c(C(c3ccccc3)c3c[nH]c4cc(C)ccc34)c[nH]c2c1</smiles><smiles>COc1ccc2[nH]cc(C(c3ccccc3)c3c[nH]c4ccc(OC)cc34)c2c1</smiles>

$90 \%$

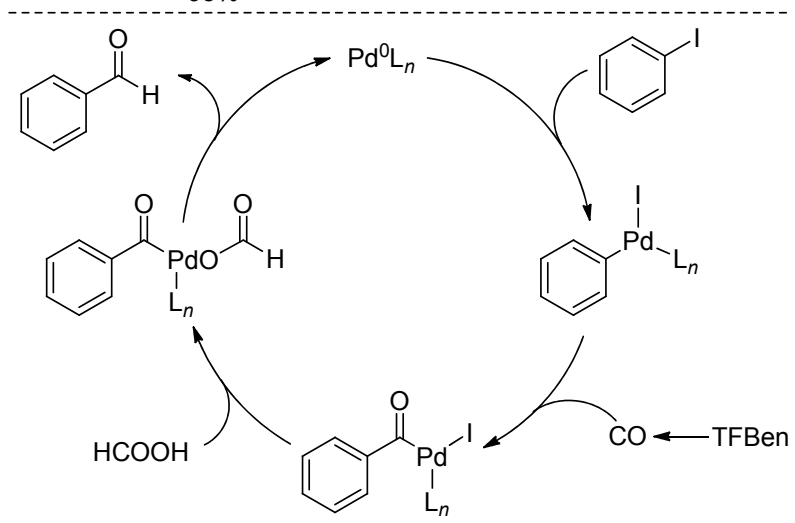

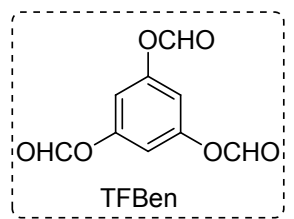<smiles>Cn1cc(C(c2ccccc2)c2cn(C)c3ccc(C=Cc4ccccc4)cc23)c2ccccc21</smiles>

Scheme 38 Synthesis of bis(indolyl)methane derivatives 
the reaction system can be divided into two parts: the first part is the reductive carbonylation of aryl iodides to produce benzaldehydes in situ; the second part is the formic acid promoted nucleophilic addition of indoles to benzaldehydes to give the final products.

\section{Summary}

Transition metal catalyzed carbonylation reactions already became the most important methods for organic synthesis in academic as well as industry. Despite various kinds of novel carbonylation reactions have been developed over the past decades, several challenge problems still exist, which need to be solved. Generally, catalyst efficiency in such reactions is still low, relatively harsh reaction conditions and additional additives are needed to activate the alternative $\mathrm{CO}$ surrogates, which mean additional cost and waste. Besides, the regioselectivity and sustainability in most cases were inefficient, and most of those cases need relatively high-pressure CO. All of these disadvantages limited the widely application of transition metal catalyzed carbonylation reactions.

What are the goals for the future years in carbonylation reactions? Regarding the $\mathrm{CO}$ sources, the inexpensive, easily available, and less toxic $\mathrm{CO}$ surrogates should be discovered and applied more in organic chemistry. Apart from metal carbonyl compounds, formic acid and aldehyde, the in situ reduction of $\mathrm{CO}_{2}$ to $\mathrm{CO}$ is the most promising method since the greenhouse effect. In addition, biomass, which is also a readily available and renewable resource, offers potential opportunities for the future research. In the case of catalysts, up until now, palladium catalysts dominate the most cases in the carbonylation reactions. The other cheap catalysts like iron, cobalt, manganese, and copper have not yet been systemically explored.

\section{References}

[1] For selected recent reviews, see: (a) Wu, X.-F.; Neumann, H.; Beller, M. Chem. Soc. Rev. 2011, 40, 4986.

(b) Gabriele, B.; Mancuso, R.; Salerno, G. Eur. J. Org. Chem. 2012, 6825.

(c) Peng, J.-B.; Qi, X.; Wu, X.-F. Synlett 2017, 28, 175.

(d) Wu, X.-F. RSC $A d v$. 2016, 6, 83831.

(e) Peng, J.-B.; Qi, X.; Wu, X.-F. ChemSusChem 2016, 9, 2279.

(f) Peng, J.-B.; Wu, X.-F. Angew. Chem., Int. Ed. 2018, 57, 1152.

(g) Peng, J.-B.; Wu, F.-P.; Wu, X.-F. Chem. Rev. 2019, 119, 2090.

[2] (a) Sigman, M. S.; Kerr, C. E.; Eaton, B. E. J. Am. Chem. Soc. $1993,115,7545$.

(b) Wu, X. F.; Jiao, H. J.; Neumann, H.; Beller, M. Chem. Eur. J. 2012, $18,16177$.

[3] Schranck, J.; Wu, X. F.; Tlili, A.; Neumann, H.; Beller, M. Chem. Eur. J. 2013, 19, 12959.

[4] Wu, X. F.; Neumann, H.; Neumann, S.; Beller, M. Tetrahedron Lett. 2013, 54,3040 .

[5] Wu, X. F.; Neumann, H.; Neumann, S.; Beller, M. Chem.-Eur. J. 2012, $18,13619$.

[6] Wu, X. F.; Zhang, M.; Jiao, H. J.; Neumann, H.; Beller, M. Asian J. Org. Chem. 2013, 2, 135.

[7] Chen, J. B.; Natte, K.; Spannenberg, A.; Neumann, H.; Beller, M.; Wu, X. F. Org. Biomol. Chem. 2014, 12, 5578.
[8] Chen, J. B.; Natte, K.; Wu, X. F. Tetrahedron Lett. 2015, 56, 342.

[9] Shen, C. R.; Spannenberg, A.; Auer, M.; Wu, X. F. Adv. Synth. Catal. 2017, 359, 941

[10] (a) Yang, Q.; Alper, H. J. Org. Chem. 2010, 75, 948. (b) Awuah, E.; Capretta, A. Org. Lett. 2009, 11, 3210 (d) Miao, H.; Yang, Z. Org. Lett. 2000, 2, 1765.

[11] Wu, X. F.; Neumann, H.; Beller, M. Chem.-Eur. J. 2012, 18, 12595.

[12] Zhu, F. X.; Li, Y. H.; Wang, Z. C.; Wu, X. F. Catal. Sci. Technol. 2016, 6, 2905

[13] Shen, C. R.; Li, W. F.; Yin, H. F.; Spannenberg, A.; Skrydstrup, T.; Wu, X. F. Adv. Synth. Catal. 2016, 358, 466.

[14] He, L.; Li, H. Q.; Neumann, H.; Beller, M.; Wu, X. F. Angew. Chem., Int. Ed. 2014, 53, 1420.

[15] Natte, K.; Neumann, H.; Wu, X. F. Catal. Sci. Technol. 2015, 5, 4474.

[16] Chen, J. B.; Natte, K.; Spannenberg, A.; Neumann, H.; Langer, P.; Beller, M.; Wu, X. F. Angew. Chem., Int. Ed. 2014, 53, 7579.

[17] Chen, J. B.; Natte, K.; Neumann, H.; Wu, X. F. Chem.-Eur. J. 2014, 20, 16107.

[18] Wu, X. F.; He, L.; Neumann, H.; Beller, M. Chem.-Eur. J. 2013, 19, 12635.

[19] Li, H. Q.; He, L.; Neumann, H.; Beller, M.; Wu, X. F. Green Chem. 2014, 16, 1336.

[20] Shen, C.; Man, N. Y. T.; Stewart, S.; Wu, X. F. Org. Biomol. Chem. 2015, 13,4422 .

[21] Shen, C. R.; Spannenberg, A.; Wu, X. F. Angew. Chem., Int. Ed. 2016, $55,5067$.

[22] Wu, X. F.; Neumann, H.; Beller, M. Chem.-Eur. J. 2012, 18, 12599.

[23] Wu, X. F.; Neumann, H.; Neumann, S.; Beller, M. Chem.-Eur. J. 2012, $18,8596$.

[24] Natte, K.; Chen, J. B.; Li, H. Q.; Neumann, H.; Beller, M.; Wu, X. F. Chem.-Eur. J. 2014, 20, 14184

[25] Wu, X. F.; Wu, L. P.; Jackstell, R.; Neumann, H.; Beller, M. Chem.Eur. J. 2013, 19, 12245.

[26] Chen, J. B.; Natte, K.; Neumann, H.; Wu, X. F. RSC Adv. 2014, 4, 56502 .

[27] Chen, J. B.; Neumann, H.; Beller, M.; Wu, X. F. Org. Biomol. Chem. 2014, 12, 5835.

[28] Li, H. Q.; Li, W. F.; Spannenberg, A.; Baumann, W.; Neumann, H.; Beller, M.; Wu, X. F. Chem.-Eur. J. 2014, 20, 8541.

[29] (a) Shen, C. R.; Wu, X. F. Catal. Sci. Technol. 2015, 5, 4433. (b) Shen, C. R.; Neumann, H.; Wu, X. F. Green Chem. 2015, 17, 2994.

[30] Li, H. Q.; Spannenberg, A.; Neumann, H.; Beller, M.; Wu, X. F. Chem. Commun. 2014, 50, 2114.

[31] Zhu, F. X.; Li, Y. H.; Wang, Z. C.; Wu, X. F. Adv. Synth. Catal. 2016, 358, 3350 .

[32] (a) Zhu, F. X.; Li, Y. H.; Wang, Z. C.; Wu, X. F. Angew. Chem., Int. Ed. 2016, 55, 14151.

(b) Zhu, F. X.; Wang, Z. C.; Li, Y. H.; Wu, X. F. Chem.-Eur. J. 2017, 23, 3276.

(c) Zhu, F. X.; Wu, X. F. Org. Lett. 2018, 20, 3422.

[33] Wu, X. F.; Sharif, M.; Shoaib, K.; Neumann, H.; Pews-Davtyan, A.; Langer, P.; Beller, M. Chem.-Eur. J. 2013, 19, 6230.

[34] Wu, X. F.; Oschatz, S.; Sharif, M.; Beller, M.; Langer, P. Tetrahedron 2014, 70, 23.

[35] (a) He, L.; Sharif, M.; Neumann, H.; Beller, M.; Wu, X. F. Green Chem. 2014, 16, 3763.

(b) Peng, J.-B.; Geng, H.-Q.; Wang, W.; Qi, X.; Ying, J.; Wu, X.-F. J. Catal. 2018, 365, 10.

[36] (a) Wu, X. F.; Oschatz, S.; Sharif, M.; Flader, A.; Krey, L.; Beller, M.; Langer, P. Adv. Synth. Catal. 2013, 355, 3581.

(b) Xu, J.-X.; Wu, X.-F. Adv. Synth. Catal. 2018, 360, 3376

(c) Zhu, F.; Li, Y.; Wang, Z.; Wu, X.-F. ChemCatChem 2016, 8, 3710.

[37] Wu, X. F.; Oschatz, S.; Sharif, M.; Langer, P. Synthesis 2015, 47, 2641.

[38] (a) Li, R.; Qi, X. X.; Wu, X. F. Org. Biomol. Chem. 2017, 15, 6905. 
(b) Qi, X. X.; Li, R.; Wu, X. F. RSC Adv. 2016, 6, 62810

(c) Qi, X.; Li, R.; Li, H.-P.; Peng, J.-B.; Ying, J.; Wu, X.-F. ChemCatChem 2018, 10, 3415.

[39] Li, W. F.; Wu, X. F. J. Org. Chem. 2014, 79, 10410.

[40] Chen, J. B.; Natte, K.; Spannenberg, A.; Neumann, H.; Beller, M.; Wu, X. F. Chem.-Eur. J. 2014, 20, 14189.

[41] Chen, J. B.; Natte, K.; Wu, X. F. J. Organomet. Chem. 2016, 803, 9.

[42] Wang, Z. C.; Li, Y. H.; Zhu, F. X.; Wu, X. F. Adv. Synth. Catal. 2016, 358, 2855.

[43] (a) Wang, Z. C.; Yin, Z. P.; Zhu, F. X.; Li, Y. H.; Wu, X. F. ChemCatChem 2017, 9, 3637.

(b) Wang, Z. C.; Zhu, F. X.; Li, Y. H.; Wu, X. F. ChemCatChem 2017, 9, 94

[44] (a) Wang, Z. C.; Yin, Z. P.; Wu, X. F. Org. Lett. 2017, 19, 4680.

(b) Yin, Z.; Wang, Z.; Wu, X.-F. Org. Biomol. Chem. 2018, 16,
3707.

[45] Qi, X. X.; Li, H. P.; Wu, X. F. Chem. Asian J. 2016, 11, 2453.

[46] Chen, J. B.; Feng, J. B.; Natte, K.; Wu, X. F. Chem.-Eur. J. 2015, 21,16370

[47] Chen, J. B.; Natte, K.; Wu, X. F. Tetrahedron Lett. 2015, 56, 6413.

[48] Wang, Z.; Yin, Z.; Wu, X.-F. Chem. Commun. 2018, 54, 4798.

[49] (a) Ying, J.; Zhou, C.; Wu, X.-F. Org. Biomol. Chem. 2018, 16, 1065.

(b) Jiang, L.-B.; Qi, X.; Wu, X.-F. Tetrahedron Lett. 2016, 57, 3368. (c) Li, C.-L.; Zhang, W.-Q.; Qi, X.; Peng, J.-B.; Wu, X.-F. J. Organomet. Chem. 2017, 838,9 .

(d) Wang, H.; Ying, J.; Lai, M.; Qi, X.; Peng, J.-B.; Wu, X.-F. $A d v$. Synth. Catal. 2018, 360, 1693.

[50] Qi, X.; Ai, H.-J.; Zhang, N.; Peng, J.-B.; Ying, J.; Wu, X.-F. J. Catal. 2018, 362, 74

(Cheng, F.) 